\title{
Increasing vegetable intakes: rationale and systematic review of published interventions
}

\author{
Katherine M. Appleton ${ }^{1}$ Ann Hemingway ${ }^{2}$ Laure Saulais ${ }^{3}$. \\ Caterina Dinnella $^{4} \cdot$ Erminio Monteleone $^{4} \cdot$ Laurence Depezay $^{5} \cdot$ David Morizet $^{5}$. \\ F. J. Armando Perez-Cueto ${ }^{6} \cdot$ Ann Bevan $^{2} \cdot$ Heather Hartwell $^{7}$
}

Received: 22 July 2015 / Accepted: 6 December 2015 / Published online: 11 January 2016

(C) The Author(s) 2016. This article is published with open access at Springerlink.com

\begin{abstract}
Purpose While the health benefits of a high fruit and vegetable consumption are well known and considerable work has attempted to improve intakes, increasing evidence also recognises a distinction between fruit and vegetables, both in their impacts on health and in consumption patterns. Increasing work suggests health benefits from a high consumption specifically of vegetables, yet intakes remain low, and barriers to increasing intakes are prevalent making intervention difficult. A systematic review was undertaken to identify from the published literature all studies reporting an intervention to increase intakes of vegetables as a distinct food group.

Methods Databases-PubMed, PsychInfo and Medlinewere searched over all years of records until April 2015 using pre-specified terms.
\end{abstract}

Katherine M. Appleton

k.appleton@bournemouth.ac.uk

1 Research Centre for Behaviour Change, Department of Psychology, Faculty of Science and Technology, Bournemouth University, Poole House, Fern Barrow, Poole, Dorset BH12 5BB, UK

2 Faculty of Health and Social Sciences, Bournemouth University, Bournemouth, Dorset, UK

3 Centre for Food and Hospitality Research, Institut Paul Bocuse, Ecully, France

4 Department of the Management of Agriculture, Forestry and Food Systems, University of Firenze, Florence, Italy

5 Food and Behaviours Department, Corporate Research and Communication, Bonduelle, Villeneuve D'Ascq, France

6 Department of Food Science, University of Copenhagen, Copenhagen, Denmark

7 Faculty of Management, Bournemouth University, Poole, Dorset, UK
Results Our searches identified 77 studies, detailing 140 interventions, of which 133 (81\%) interventions were conducted in children. Interventions aimed to use or change hedonic factors, such as taste, liking and familiarity $(n=72)$, use or change environmental factors $(n=39)$, use or change cognitive factors $(n=19)$, or a combination of strategies $(n=10)$. Increased vegetable acceptance, selection and/or consumption were reported to some degree in $116(83 \%)$ interventions, but the majority of effects seem small and inconsistent. Conclusions Greater percent success is currently found from environmental, educational and multi-component interventions, but publication bias is likely, and long-term effects and cost-effectiveness are rarely considered. A focus on long-term benefits and sustained behaviour change is required. Certain population groups are also noticeably absent from the current list of tried interventions.

Keywords Vegetables $\cdot$ Interventions $\cdot$ Systematic review $\cdot$ Published literature

$\begin{array}{ll}\text { Abbreviations } \\ \text { C } & \text { Comparison } \\ \text { I } & \text { Intervention } \\ \text { V } & \text { Vegetable } \\ \text { vs } & \text { Versus } \\ \text { w } & \text { Weeks } \\ \text { m } & \text { Months }\end{array}$

\section{Introduction}

Health benefits of high fruit and vegetable intakes

The health benefits of a high consumption of fruits and vegetables are well known [1]. Associations with all-cause 
mortality $[2,3]$ and mortality from cardiovascular disease $[2,3]$, including coronary heart disease [4] and stroke [5, 6], are well evidenced. Associations also suggest a reduced risk of hypertension [7], osteoporosis [8], body weight and adiposity [9, 10], dementia and cognitive decline [11, 12], and some cancers [13-15], although the evidence for cancers is less consistent [1,3]. Intervention studies increasing the consumption of fruits and vegetables also demonstrate improved microvascular function [16], improved microvascular function and inflammatory status [17], improved profiles in inflammatory and oxidative stress [18], improved immune response [19], and improved weight maintenance [20].

\section{Consideration of fruits and vegetables as different food groups}

However, while fruits and vegetables share health benefits as a result of the provision and interaction of a number of bioactive compounds, including vitamins, minerals, antioxidants, carotenoids and flavenoids [21, 22], the specific bioactive compounds in fruits and in vegetables can vary greatly [21-25]. Their contribution to other dietary features also vary. Fruits typically contain greater dietary sugars, with potential negative impacts on both health and on public willingness to consume them [22, 26]. Vegetables, by comparison, can contain more protein and fibre [22] and are more often processed prior to consumption. This processing can both increase and decrease micronutrient bioavailability and activity, again impacting on health benefits [22, 25, 27-31]. Many studies that separate fruits and vegetables find different effects of the different food classes on health outcomes [2, 12, 32-35]. These differences between fruits and vegetables argue for the consideration of fruits and vegetables, in terms of health, as separate and different food types.

While differing in their potential health benefits, fruits and vegetables also taste very different, are generally of a different texture and are typically consumed in different manners [36-39]. Fruit is generally sweet, is typically softer in texture, is more often consumed raw, is more frequently consumed and is generally considered more acceptable as a snack, as a drink or as dessert [36-39]. Vegetables, by comparison, can taste bitter, are generally harder in texture, are more often cooked, are more typically consumed and considered more acceptable as part of a meal [36-39], and thus are also more often consumed with other foods as opposed to alone [40]. These different consumption patterns suggest that fruit and vegetable consumption may be differentially determined. Glasson et al. [41] directly compared the determinants of fruit consumption and vegetable consumption in an Australian population, to find fruit consumption to be largely prevented by cost, food preferences, quality, availability and wastage concerns, while vegetable consumption was more frequently prevented by food preferences, lack of time, cost and taste. Differential determinants again argue for the consideration of fruits and vegetables, as separate and different food types, and suggest the potential need for different intervention strategies for increasing fruit and for increasing vegetable consumption.

Furthermore, while population levels of both fruit and vegetable consumption remain below World Health Organization recommendations across the world [42, 43], interventions to increase fruit and vegetable intakes more often target fruit, and typically report greater success for fruit consumption compared to that for vegetables, for both children and adults [44-46]. These findings suggest not only a need for different intervention strategies for increasing fruit and increasing vegetable consumption, but a real need for strategies that achieve successful increases in vegetablespecific consumption. This paper focuses specifically on vegetable consumption.

\section{Vegetable-specific consumption}

\section{Health benefits of high vegetable-specific intakes}

Various studies demonstrate health benefits from a high consumption specifically of vegetables (i.e. from vegetables alone, as opposed to in combination with fruits, as occurs when considering fruits and vegetables together). Observational studies demonstrate reduced risk of cardiovascular disease [2], type II diabetes [34], non-gallstonerelated acute pancreatitis [33], various cancers [2, 47-50] and cognitive decline [32]. Meta-analyses of observational studies demonstrate associations between a higher vegetable consumption and reduced risk of stroke [6], dementia and cognitive decline [12], and from various cancers [14, $15,35,51,52]$, although again the evidence for cancers is inconsistent. Meta-analyses of prospective studies find no benefits for breast cancer risk [53], gastric cancer risk [54], pancreatic cancer risk [55] and bladder cancer risk [56]. Meta-analyses also report no benefits of overall vegetable consumption for type II diabetes [57-59], although doseresponse meta-analyses also suggest benefit up to 2-3 servings/day and a threshold beyond this where type II diabetes risk does not reduce further [60].

Specific vegetable groups or types of vegetables have also been associated with improved health outcomes. Intakes of dark green leafy vegetables have been associated with reduced risk for type II diabetes [57-59], reduced risk for a number of cancers $[48,49,61]$ and with reduced depression [62]. High intakes of cruciferous vegetables have been associated with reduced risk from various cancers [63-70]. Intakes of beta-carotene-rich vegetables, 
yellow- and red-pigmented vegetables, and fruiting vegetables have also been associated with reduced risk from various cancers [48-50, 61], and root vegetable consumption has been associated with reduced type II diabetes risk [60].

Much of this evidence, however, stems from limited studies, and the body of evidence is far from conclusive $[64,66]$. Prospective and cross-sectional studies are easily criticised for potential confounding, case control comparisons may suffer from bias towards differences between groups due to comparisons between cases and health conscious (and consequently) healthy controls [71], and study designs do not allow determination of causality. Considerable further work is required before conclusions can be drawn. The majority of studies investigating effects of vegetable consumption, furthermore, do not investigate vegetable consumption independent of fruit consumption or other aspects of the diet. While fruits and vegetables are frequently consumed together, associations may reflect not just associations with vegetables, but associations with produce consumption in general, or with a healthier diet/ lifestyle [1, 72]. A recent systematic review by Fulton et al. [72] reports impacts for fruit and vegetable interventions not only from micronutrient intakes but also from changes to the whole dietary profile. Lifestyle factors are frequently included in studies as confounders, but it is often difficult to control for all potential confounders, and adjustment for other dietary aspects, particularly fruit consumption, is less common. Associations will also depend on the definition of vegetables used, and the inclusion or not of certain vegetables in certain categories. Potatoes, for example, are sometimes included among vegetables, sometimes included as 'white' vegetables, and sometimes not considered at all [21, 22].

Thus, for improved health, increasing intakes of vegetables are required. For intakes of vegetables to be increased, strategies and interventions are needed. These interventions should be based on in-depth understanding of the underlying determinants of low vegetable consumption.

\section{Determinants of vegetable-specific consumption}

Various research has been undertaken to understand the associations with, and reasons for, vegetable consumption, independent of fruit consumption. In young children, the bitter and undesirable taste of vegetables is often provided as a major barrier to vegetable consumption [73-75], and food neophobia (the reluctance to eat, or the avoidance of, novel foods [76]) particularly, can interfere with young children's acceptance of vegetables [76-78]. This neophobia typically results in the rejection of bitter tasting foods and foods that do not "look right" [76], of which vegetables are good examples.
As children age, taste, appearance and liking continue to be important [79], but low vegetable consumption is frequently also associated with various characteristics of the family environment. These factors include low parental education and socio-economic status [80-82], low vegetable consumption by parents and caregivers [83-85], low availability and negative perceptions of vegetables in the home [86] and a family environment that is unsupportive of vegetable consumption [83, 85, 87]. Vegetable consumption is higher, for example, in families where vegetables are disguised or sauces are used to mask undesirable tastes and appearances [79, 83, 85], where vegetables are more often incorporated into composite foods as opposed to consumed alone to dilute negative tastes and appearances [79], where meals are home cooked to accommodate individual preferences [83], and where games are played to encourage vegetable consumption [85]. The expression of neophobic behaviour towards vegetables also appears to be mitigated by high parental education and high socio-economic status [77, 88] and again by a positive and supportive environment $[89,90]$.

Taste, appearance, liking and the surrounding environment continue to be important as children become adolescents, but individual cognitions also gain increasing importance. Low vegetable consumption in adolescents has again been associated with low parental education and socio-economic status [91], low vegetable consumption by the parents [92], low availability and a family environment that is unsupportive of vegetable consumption [91, 93]. Vegetable consumption in adolescents, however, has also been associated with an awareness of the importance of vegetables for health, and a willingness and ability to ask for vegetables from parents [93].

In adults, higher vegetable consumption has been associated with higher liking for the taste of vegetables [41, 94, 95], higher appreciation of health and the value of a healthy diet [94], greater nutritional and culinary knowledge [96, 97], and with several related food habits and eating practices [98, 99], including usual consumption of meals as opposed to snacks [94, 100], increased time and willingness to prepare and cook home-cooked meals [41, 94, 95, 97], and a low consumption of fast food [94]. The transfer of childhood eating habits and food preferences into adulthood is well known, and adult vegetable intake is often related to childhood experiences [94]. Neophobic tendencies also typically last well into adulthood, and typically correlate negatively with liking for and frequency of vegetable consumption in adulthood [101-103]. The individual preferences of one family member can also have impacts on the rest of the family, with most family units opting to cook only one meal of acceptability to all family members $[104,105]$. Given the importance of adult consumption for 
children, many of the determinants of adult consumption will also impact on child consumption.

Alongside individual preferences, higher vegetable consumption in adults is also related to increased availability [98, 106, 107] and reduced cost $[41,95,97,108]$, and low consumption is largely associated with lower socio-economic status [109, 110], lower income [44, 107], living in a more deprived area or lower income neighbourhood (an indirect measure of socio-economic status) [44] and lower education $[109,111]$.

Research thus, suggests a variety of reasons behind low vegetable consumption, ranging from taste and pleasure, to individual cognitions and health beliefs, and to aspects beyond the individual including society and the environment. Many of these reasons have been targeted by interventions.

\section{Strategies to increase vegetable-specific consumption: systematic review}

Various reports of strategies to increase vegetable-specific consumption are available. A comprehensive collection of these interventions, and an evaluation of success, however, is currently lacking. The aim of this work was to systematically review the published literature to identify all published interventions aiming to increase vegetable-specific consumption.

\section{Method}

The objective of the review was to identify from the published literature all studies reporting an intervention to increase vegetable intakes, where vegetables were considered as a separate and distinct food group, and the intervention focused specifically on increasing intakes of this food group. Three databases: PubMed, PsychInfo, and Medline, were searched over all years of records for all studies with the terms 'vegetable' and 'vegetables' in the 'title'. These search criteria were used to limit the search results to studies with a focus on vegetables. No other search criteria and no limits were used. All titles were screened for relevance and then all abstracts. Two review authors independently conducted all searches, screened all titles and screened all abstracts (KMA, AH or HH). Studies were included in the review if they involved an intervention designed primarily to increase vegetable intakes as a specific and distinct food group, and if they intended to change behaviour-vegetable selection, purchasing or vegetable consumption. Studies were not included if they did not include an intervention, if the intervention targeted fruit and vegetable intakes [112], if the intervention targeted vegetables and other foods, e.g. vegetables and wholegrains [113, 114]; if the intervention involved changing consumption as opposed to increasing consumption [115], or if they did not include a measure of behaviour, but instead only measured correlates of behaviour such as intentions, attitudes, and knowledge $[116,117]$. Studies measuring tasting were included where tasting was voluntary, where amount tasted was voluntary and where tasting/amount was measured, but studies where tasting was compulsory and/or prespecified, e.g. to make hedonic judgements, were not included [118, 119]. Studies were included regardless of the use or not of a comparison for an intervention, or the type of comparison used. A study using a vegetable-specific intervention that is compared with a fruit-specific intervention, for example, is included [120] (all other criteria were also met). Relevant articles were also searched for other suitable studies. Searches of conference abstracts, book chapters, etc., were not undertaken, thus studies are only included if reported in full articles. Details from all studies were subsequently tabulated by one review author (KMA) and checked by an additional review author ( $\mathrm{AH}$ or $\mathrm{HH}$ ). All tables are provided in the "Results" section. No other data were extracted. Due to the early nature of the research area, the limited number of studies available per intervention type, and high heterogeneity between study methodologies, risk of bias was not assessed, and no attempt was made to combine studies, e.g. through meta-analysis. The review was undertaken using PRISMA guidelines and a PRISMA diagram illustrating the outcomes of the review process is given in Fig. 1.

\section{Results}

Searches were most recently conducted on 28 April 2015. The results of the searches are given in the PRISMA diagram in Fig. 1. A total of 77 studies were identified, reporting the impacts of 140 interventions. Details of all studies are presented by intervention type in Tables 1, 2, 3, 4, 5 and 6 . Interventions have been broadly classified as those focussing on hedonic determinants of vegetable intake, such as taste, familiarity and liking-Tables 1, 2 and 3, those focussing on environmental determinants of vegetable intake-Table 4, those focussing on cognitive determinants-Table 5, and those using a combination of approaches-Table 6 . Studies reporting two or more different interventions are included separately in separate tables, where appropriate. Within each table, studies are ordered by age of target audience. Of the interventions identified, $113(81 \%)$ interventions focus on improving intakes in children. Early intervention will maximize health benefits [45], and eating habits in childhood are likely to extend into adulthood [75, 94]. 


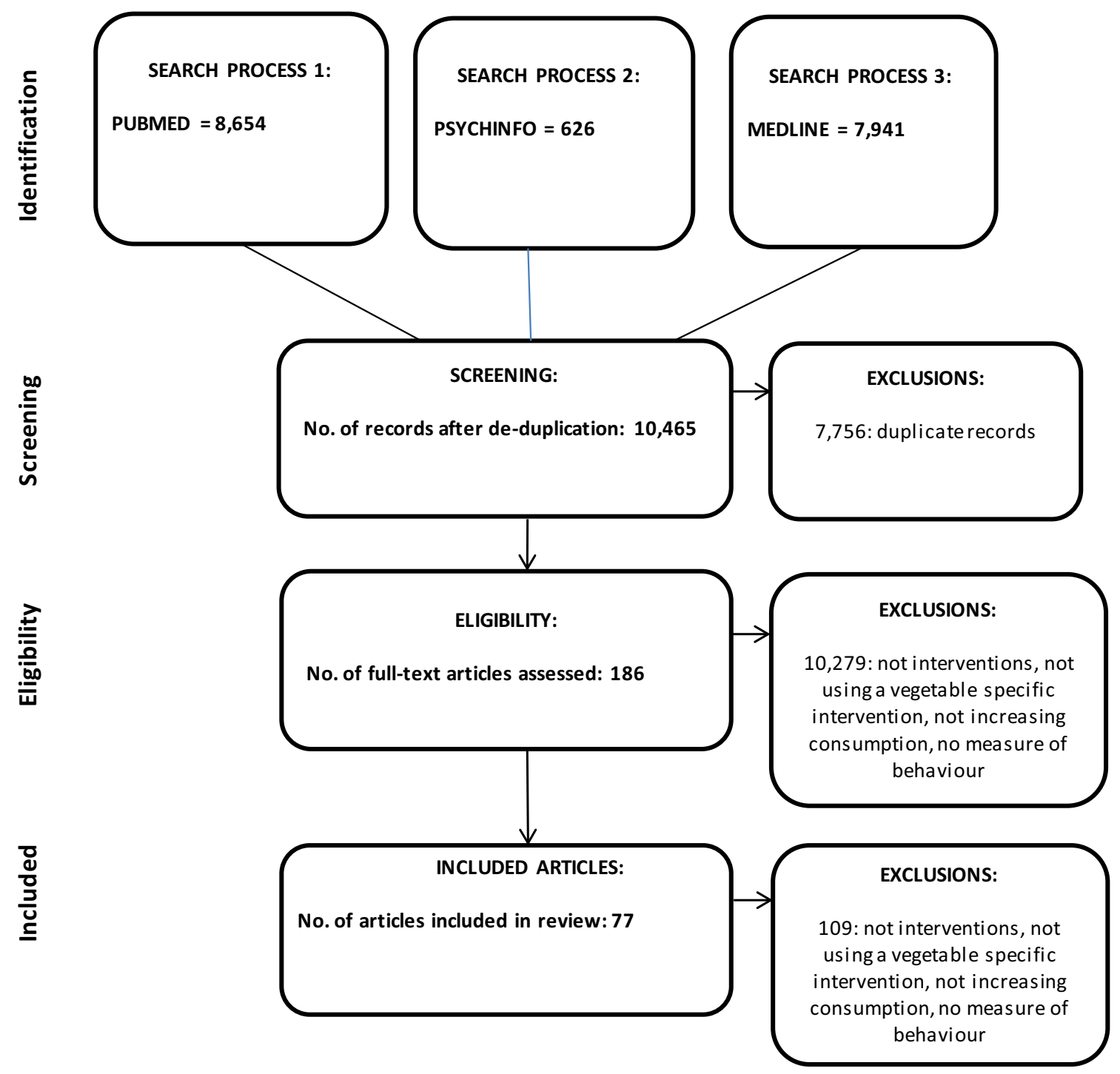

Fig. 1 PRISMA diagram showing the results of the search process

\section{Interventions aiming to change or use hedonic factors}

Eleven interventions focus on changing or using the taste or familiarity of a vegetable/vegetable product on a single occasion (Table 1). Six of these interventions suggest that the addition of a liked taste or flavour in the form of salt [121, 123] and in the form of a flavoured dip [122] or condiments [125] can increase vegetable consumption on a single occasion. Guidelines regarding salt intake and the possible impact of increasing preferences for salty flavours must also be considered, but these studies demonstrate a potentially useful strategy. The addition of fat to a vegetable product did not result in increased intakes [121], but increased intakes were found following the use of familiar as opposed to novel vegetables products [124].
Fifty-two interventions focus on increasing liking and familiarity with repeated experience. These interventions use learning techniques, including repeated exposure ( $n=23)$, ensuring that exposure is positive via pairing with liked flavours $(n=14)$, pairing with beneficial nutrients $(n=6)$, pairing with external reinforcement $(n=7)$, the use of positive models $(n=1)$ and the use of reinforcement plus models $(n=1)$ (Table 2). Many of these interventions demonstrate success by improving liking and/or consumption: 16 of $23(70 \%)$ using repeated exposure; 12 of $14(86 \%)$ using pairing with liked flavours; four of six (67\%) using pairing with nutrients; all seven $(100 \%)$ using pairing with reinforcement; and the one (100\%) using reinforcement plus modelling. Effects, however, are far from robust or consistent (i.e. effects are often found in one measure, but not in 
others), are often small, and tend to be limited to the specific vegetable used during exposure. Conditions within studies, furthermore, are often confounded, making mechanisms difficult to elucidate. In many studies that purport to investigate exposure, the exposure is in combination with other food components [129], modelling [75] or rewards in the form of praise or other positive interactions [139], thus effects may in fact occur partly due to conditioning. In many studies that purport to measure conditioning, exposure is not controlled for $[136,151]$. Many of these interventions furthermore also involve children's parents, and so may have benefits not just by allowing tasting and experience for the child, but also by improving parental perceptions of vegetables, improving attitudes towards vegetables in the home, and improving parental education and knowledge [75]. Interestingly, some of the interventions included in Table 2 report parental opinions of the intervention [75, 129], but as far as we can tell, none specifically tested parental knowledge or education as a result of the intervention for their children.

While largely successful, particularly over considerable exposures, exposure, however, is a relatively time-consuming practice that results in small changes, and typically only for the vegetable to which children have been exposed. Nine interventions have extended the use of exposure to consider exposure to vegetables via picture books and stories (Table 3). These procedures appear beneficial, although few studies have currently tested these ideas, and effects again appear small or unreliable, and typically only apply to the vegetable to which the child has been exposed. Little evidence suggests that effects generalise to other vegetables, so neither taste or visual exposure appears to encourage consumption of a variety of vegetables. Repeated exposure to many vegetables may result in increased consumption of many vegetables, and some studies are beginning to demonstrate these effects [156, 157], but generalisation of exposure to non-exposed vegetables has not yet been demonstrated reliably either through the use of taste or visual stimuli. The potential for exposure to multiple as opposed to single vegetables at one time point, however, may be greater using visual as opposed to taste stimuli.

\section{Interventions based on changing the environment}

An alternative approach to encourage vegetable consumption focuses on changing the environment and increasing consumption through increasing the provision of vegetables, or improving the manner in which provision is implemented (Table 4). Thirty-nine interventions were found using these strategies. All of these, with the exception of three interventions (one increasing variety [158] and two improving presentation [141, 164]) resulted in increased selection and/or consumption of vegetables in children and adults, through the increased provision of vegetables $(n=20)$, through the increased provision of a variety of vegetables $(n=7)$, through improved presentation $(n=5)$, through changing the location of vegetables $(n=1)$, through changing the order in which vegetables and other foods are served $(n=1)$ and through changing the serving order, while also increasing availability $(n=2)$. Increased consumption as a result of increased provision is unsurprising, but concerns have been raised regarding increased energy intakes as a result, and increased potential for food wastage. An absence of effects on overall energy intakes is reported in some studies [161], and concerns are mitigated if vegetables are substituted for other foods in the meal as opposed to simply added [161]. Suggestions to reduce potential food wastage include the use of family style serving dishes for individual meals [159, 161] or allowing differential selection, but again the costeffectiveness of interventions that can increase waste will be questioned. Strategies that improve the presentation of vegetables may offer a valuable alternative. These interventions typically change the salience or likely appeal of vegetables [141, 164, 166], and have again demonstrated success, but relatively few studies are currently available. Exact mechanisms are again unclear-attractive labels may rely partly on modelling, effects due to serving order may rely partly on hunger and exposure, but the relative ease and low cost of these interventions add to their value.

\section{Interventions based on changing or using cognitive factors}

Nineteen interventions were found that used information, education or other cognitive techniques (Table 5). These interventions are largely aimed at older audiences (those where cognitive factors have a greater impact on vegetable consumption and non-consumption), and used a range of techniques from providing information and education on nutrition $(n=6)$ or nutrition-related skills $(n=2)$, providing education plus a demonstration $(n=1)$ or gardening experience $(n=2)$, providing tailored information $(n=2)$, providing information on social norms $(n=1)$, invoking choice $(n=4)$ and invoking a memory $(n=1)$. With the exception of one intervention that aimed to educate [75], and two interventions that utilised choice [174], all of the studies using these types of strategy reported success to some degree, but multiple measures of impact were often taken, and success is not necessarily reported for all measures. The cost-effectiveness of these types of interventions is, however, also often questioned. Educational interventions can be costly, particularly those involving classes or courses to be delivered by a professional, but the long-term benefit of these interventions can also be difficult to assess. Knowledge accumulates over time and experience, and it can be difficult for individuals to pinpoint the exact source/ sources of beneficial education. 


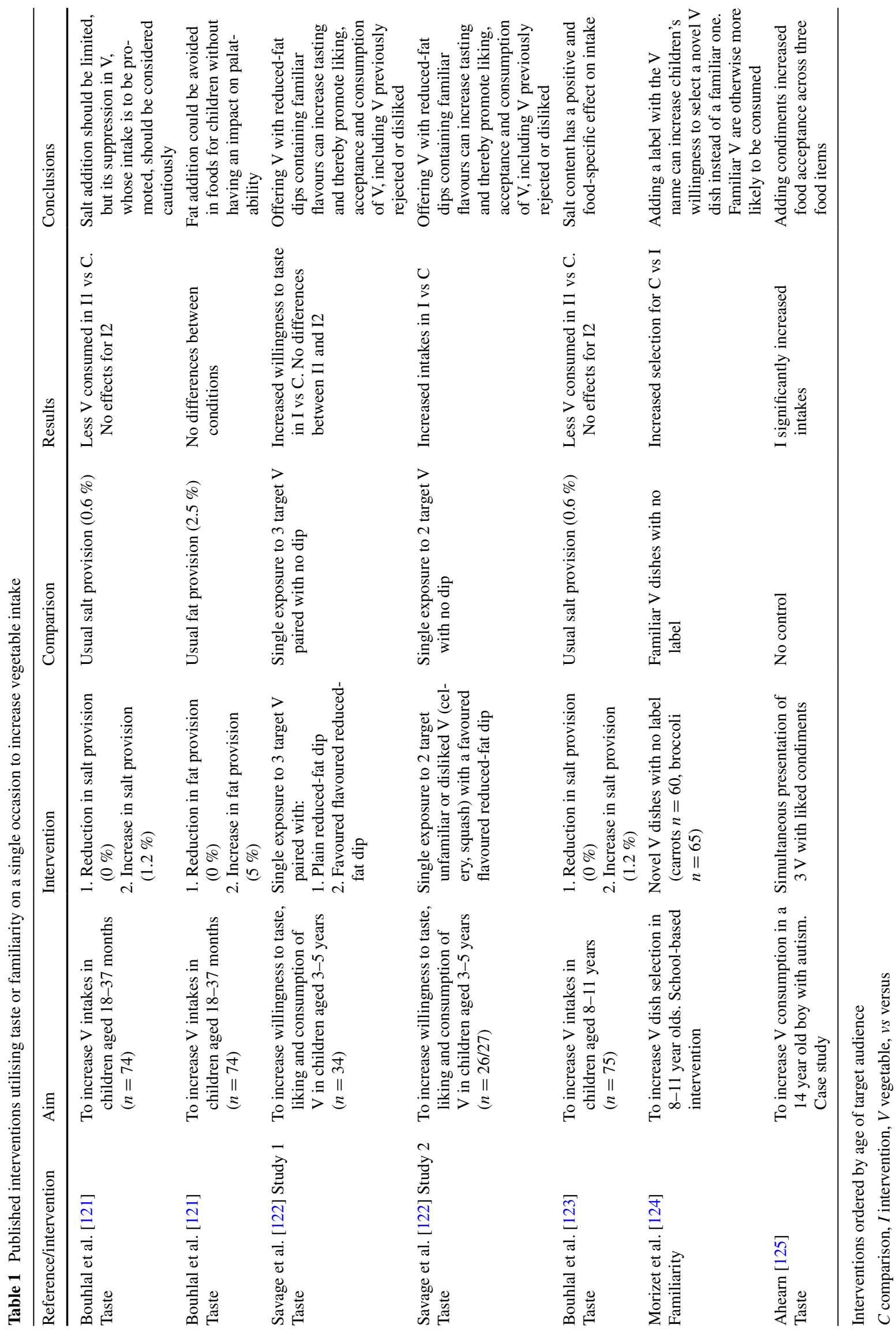




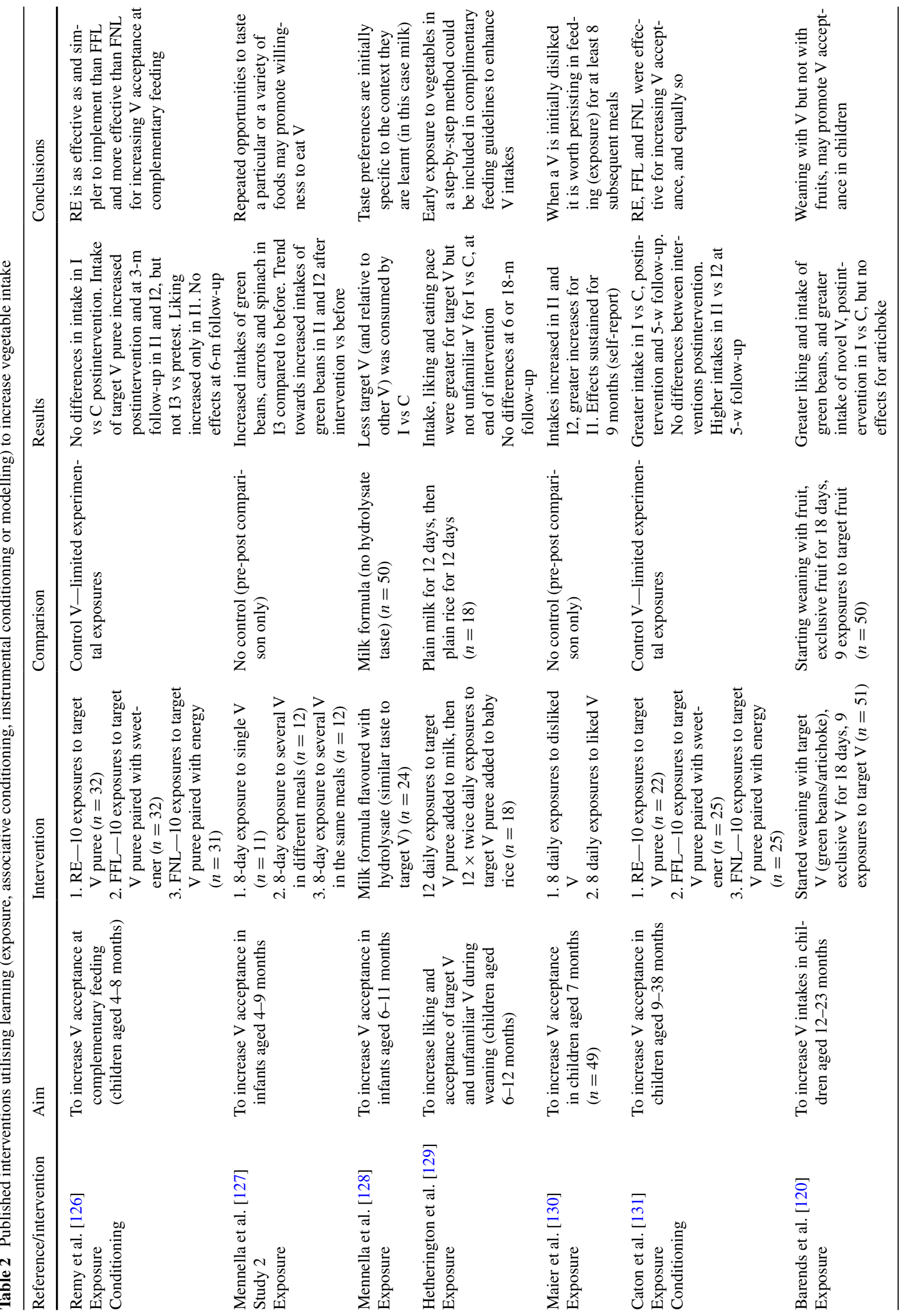




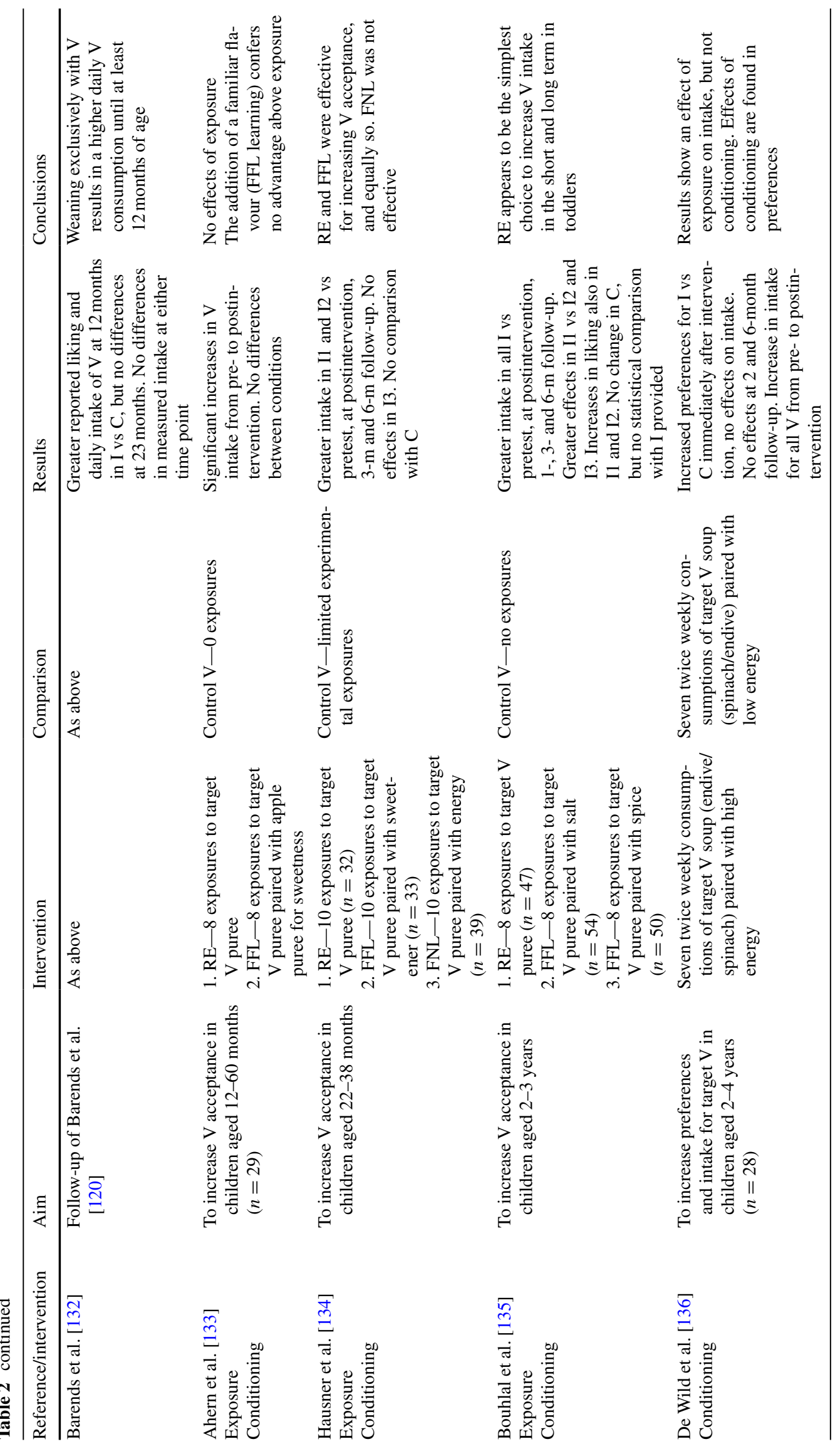




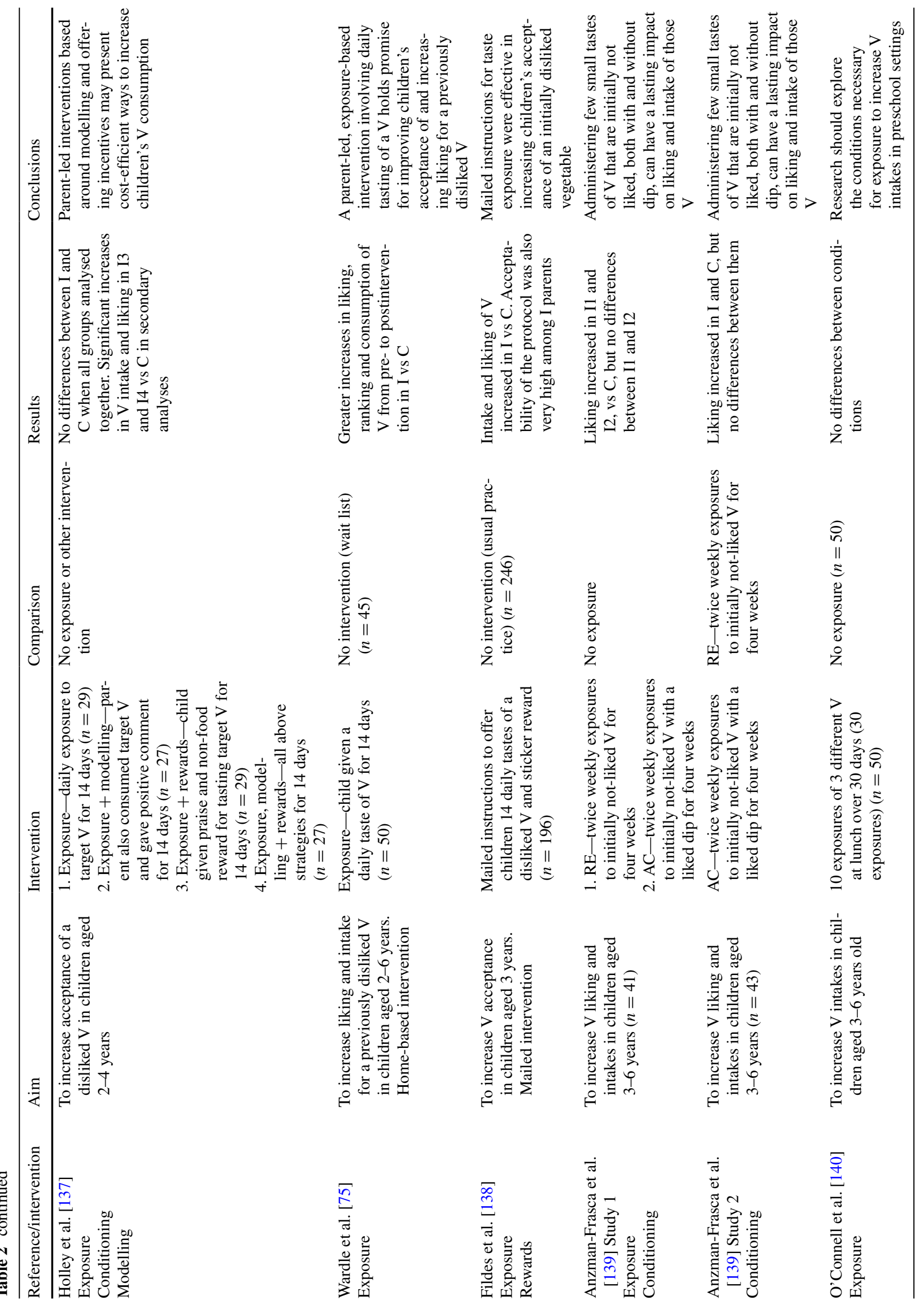




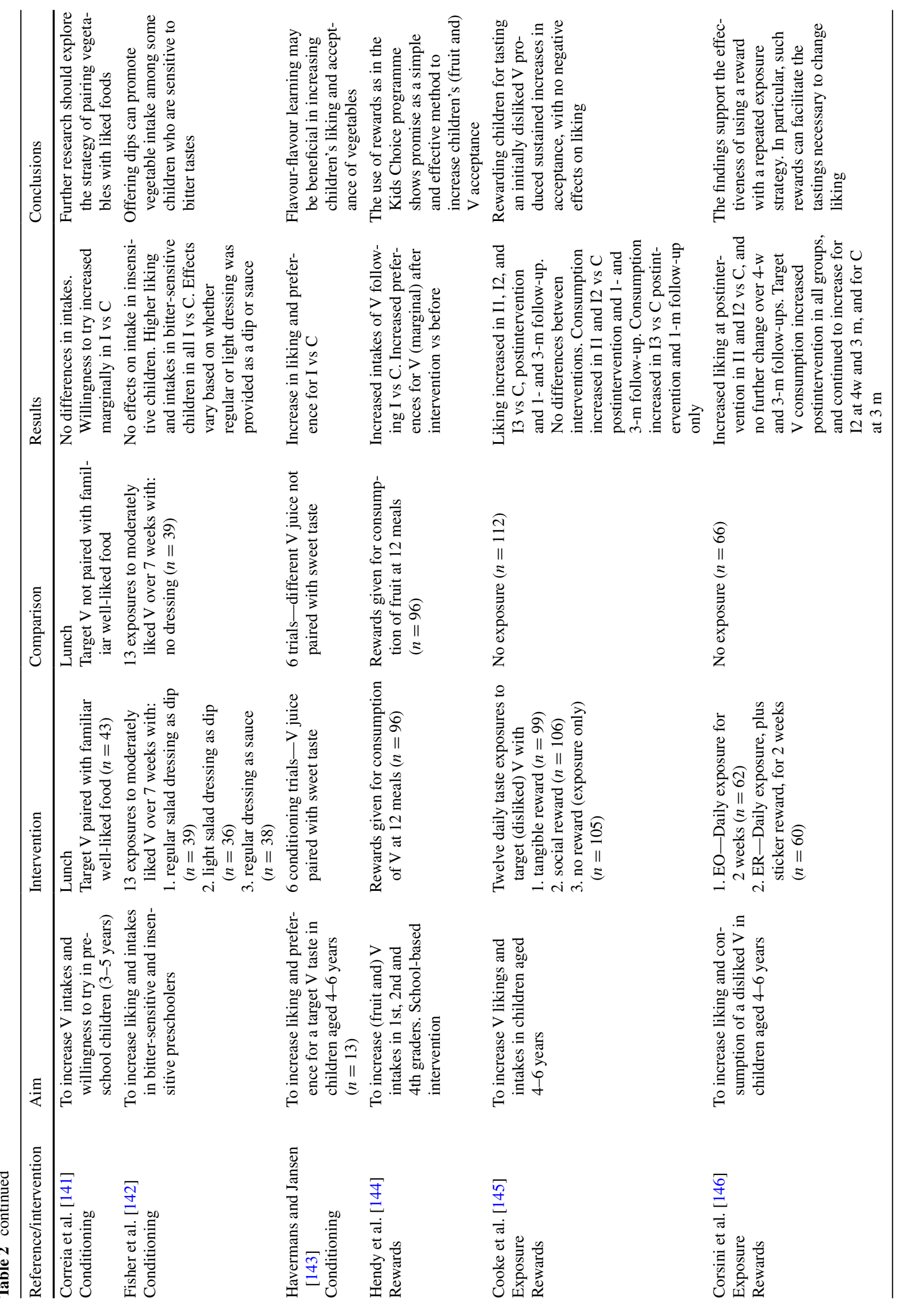




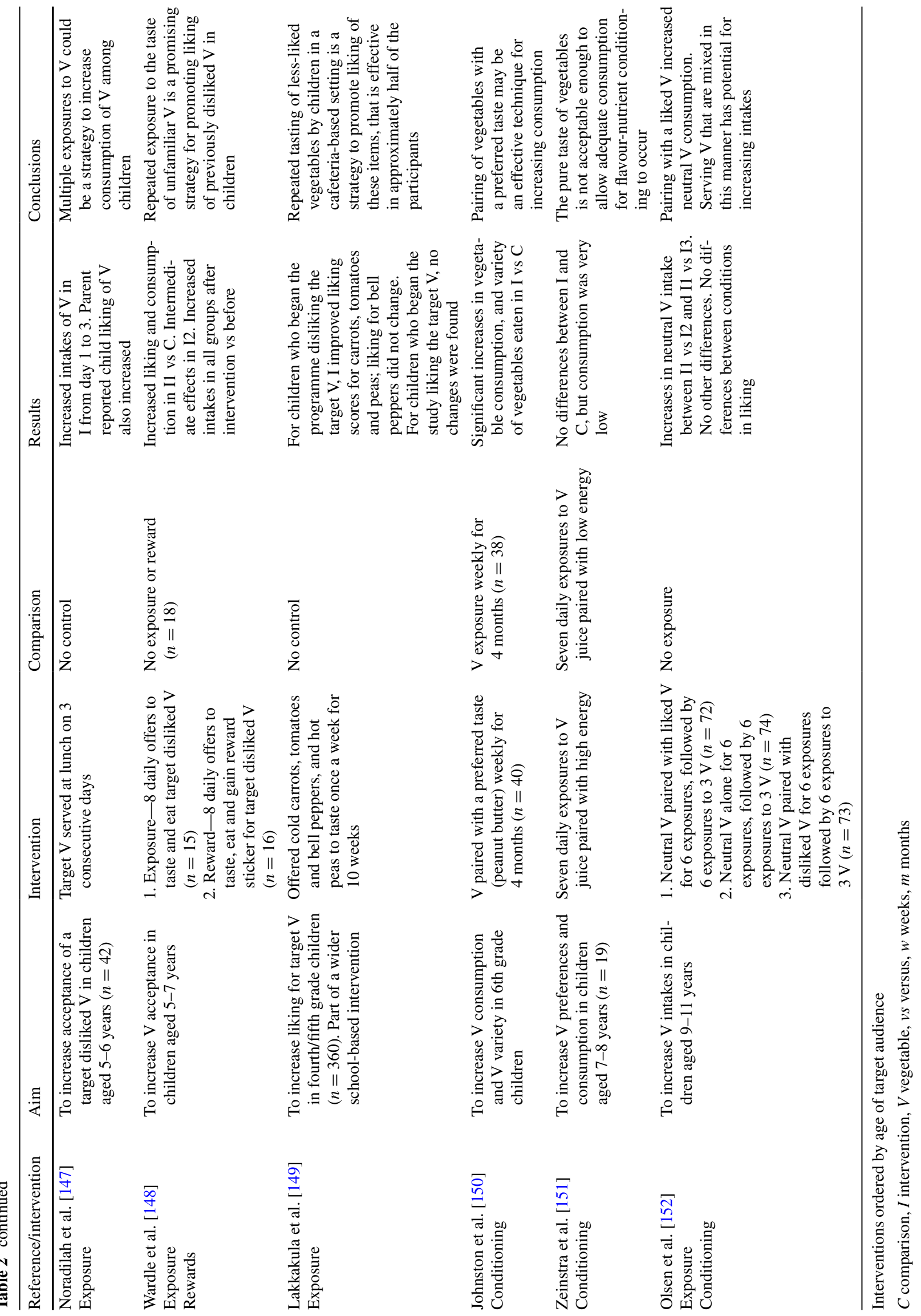




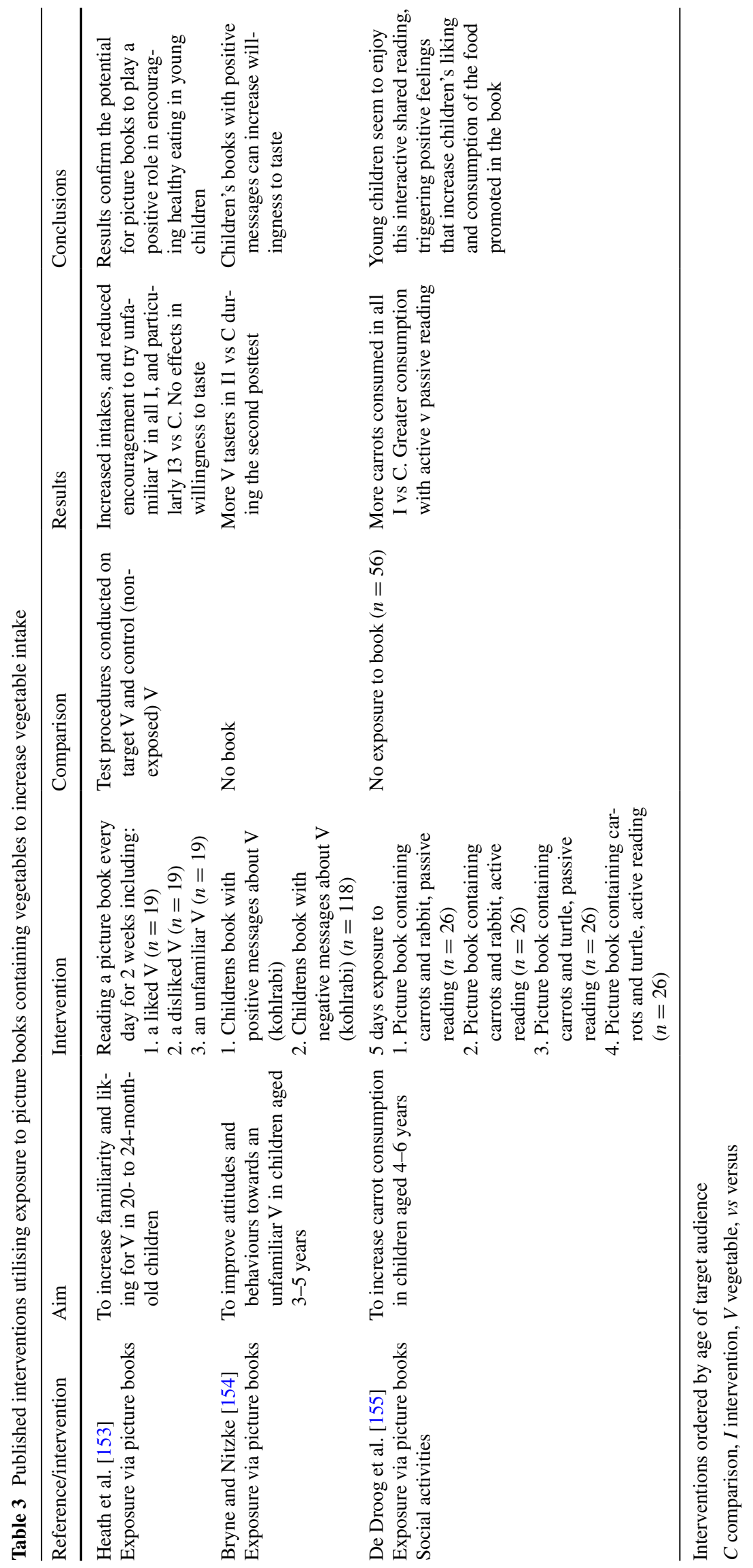




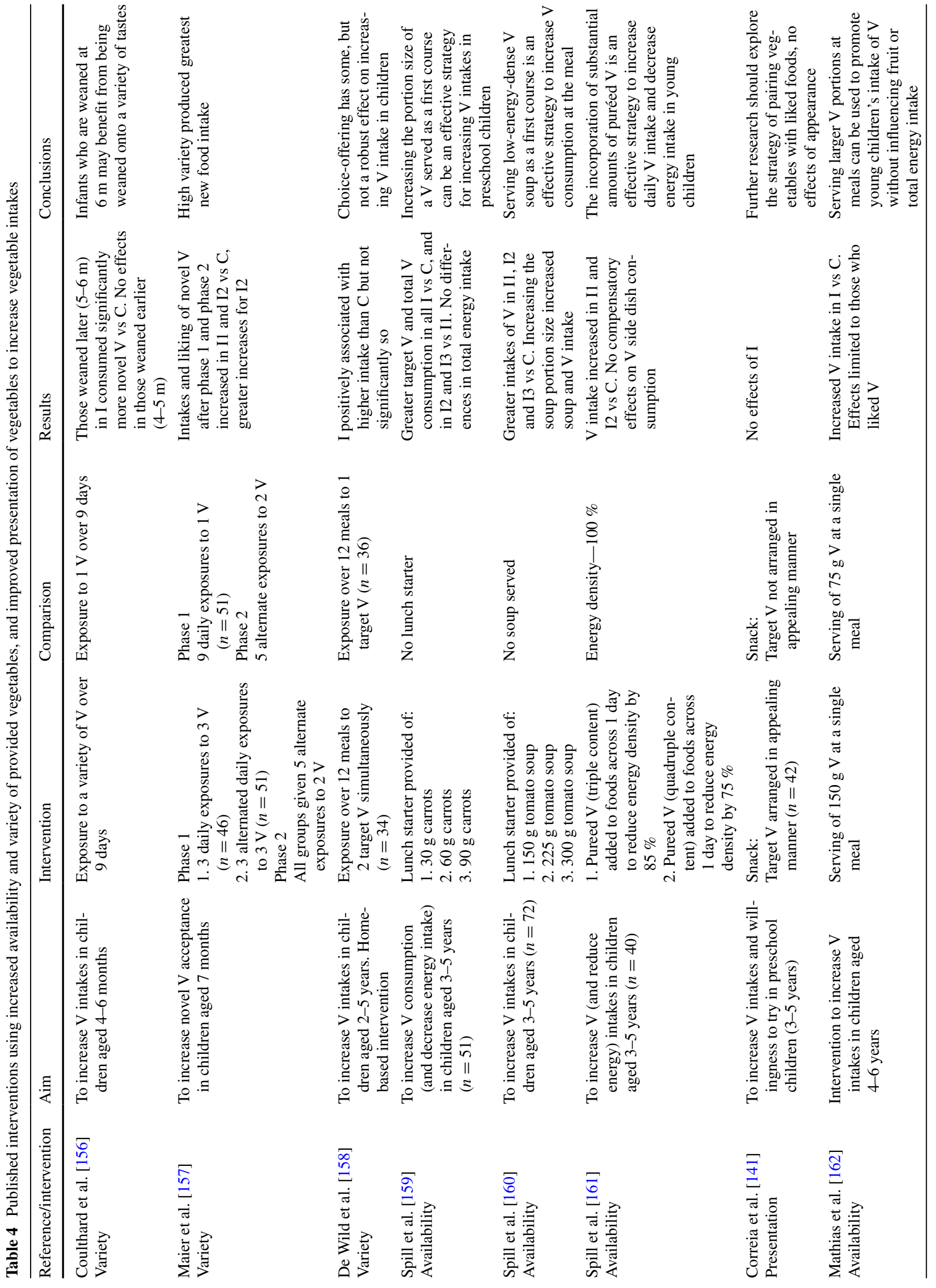




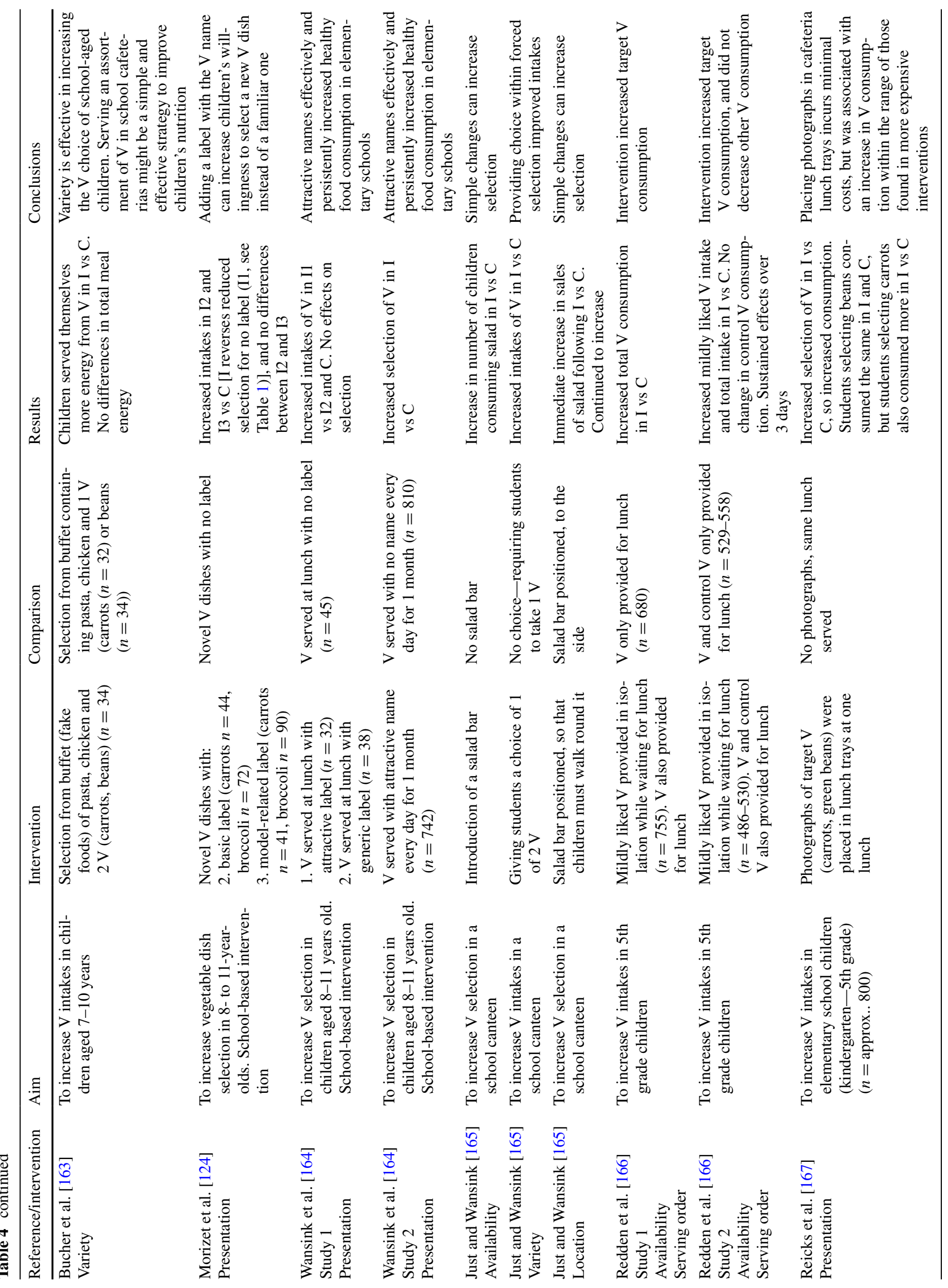




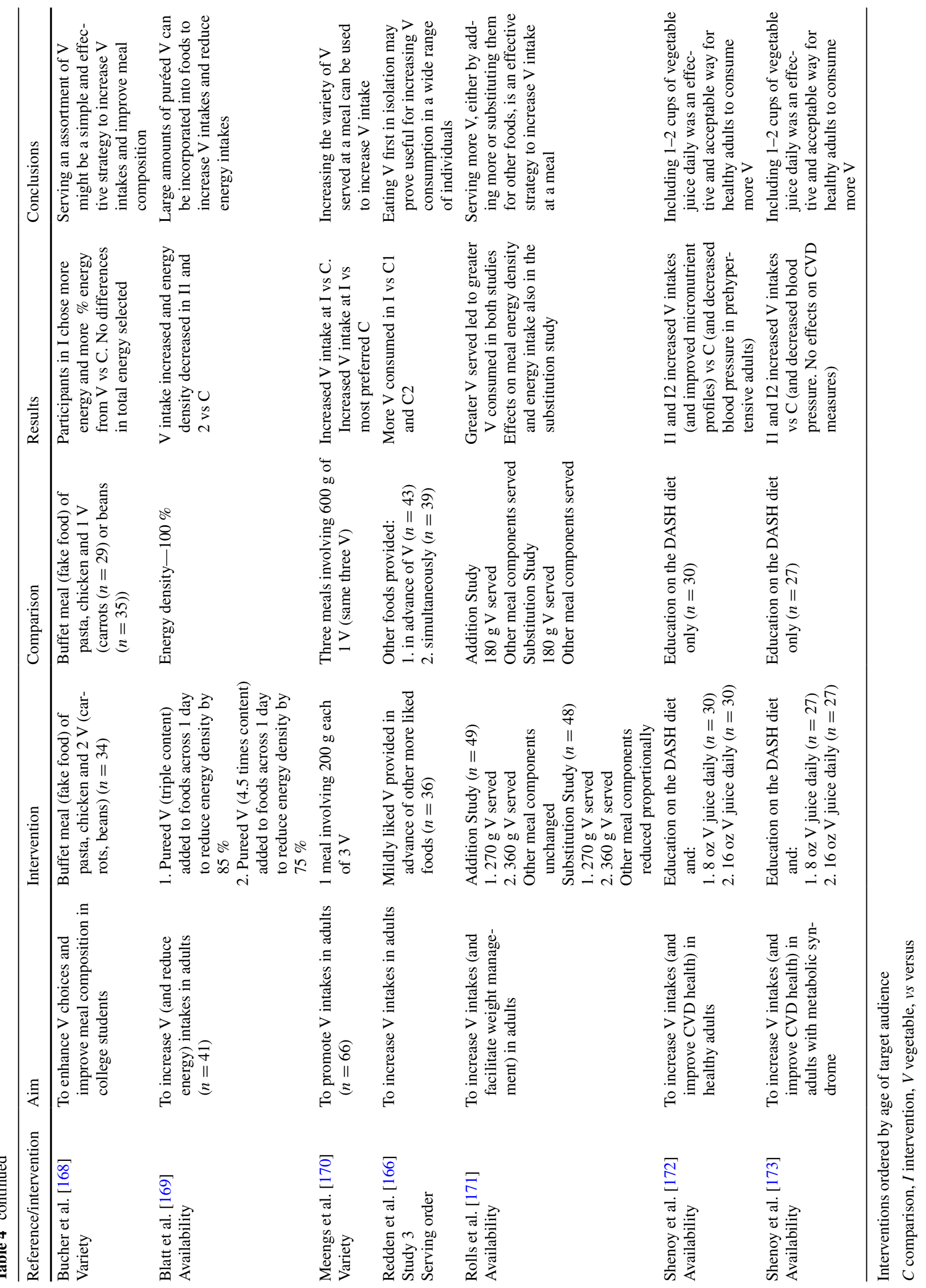




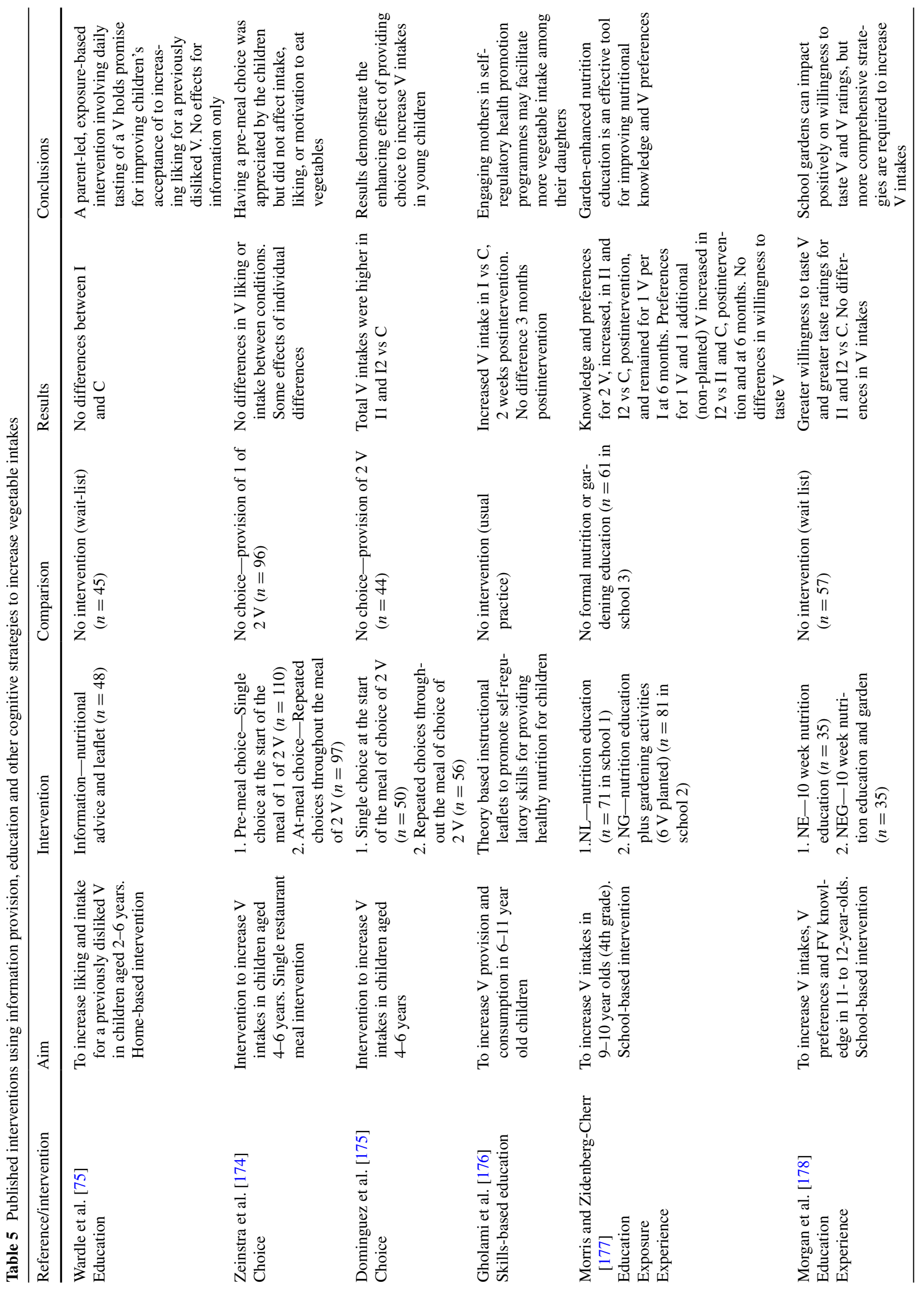




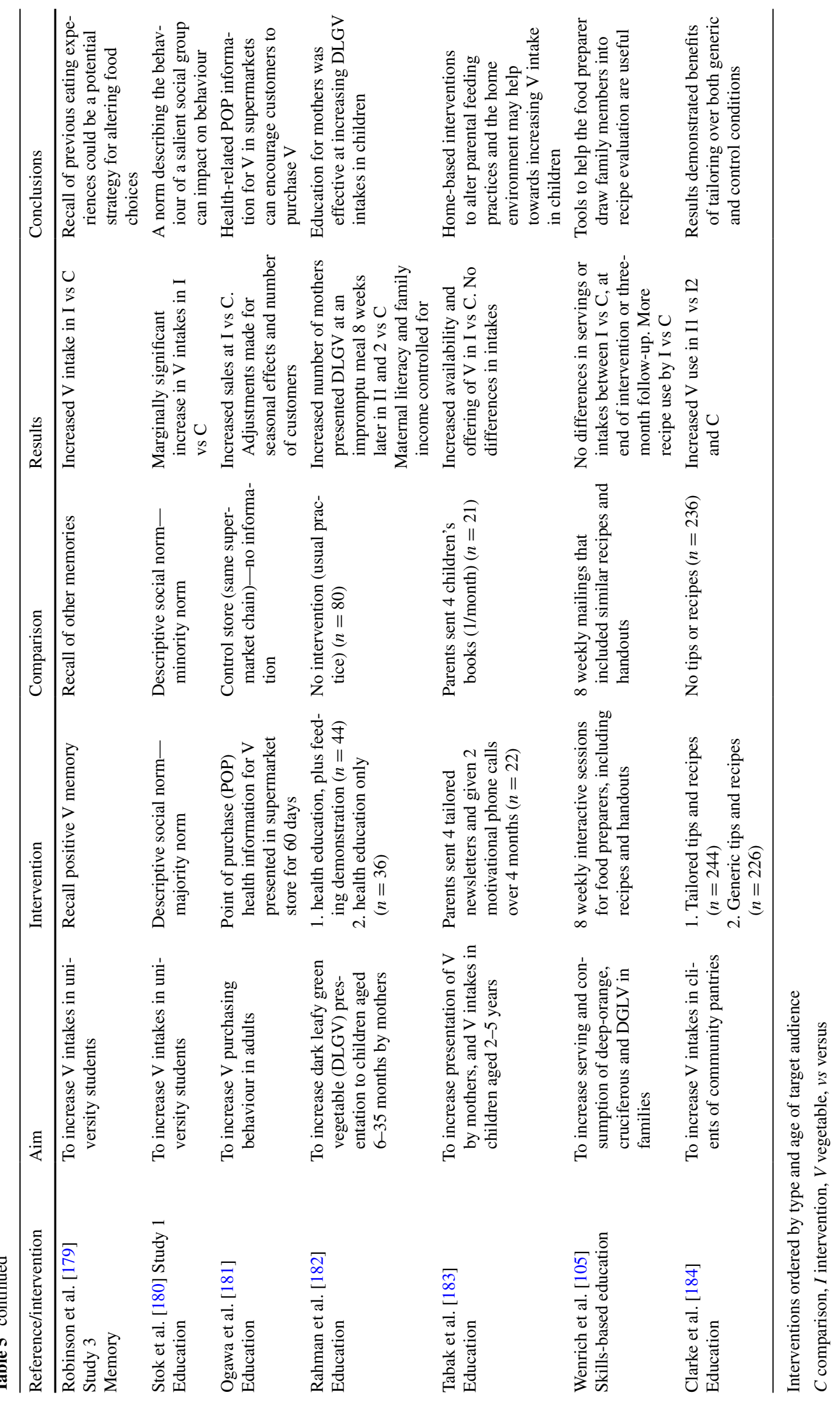




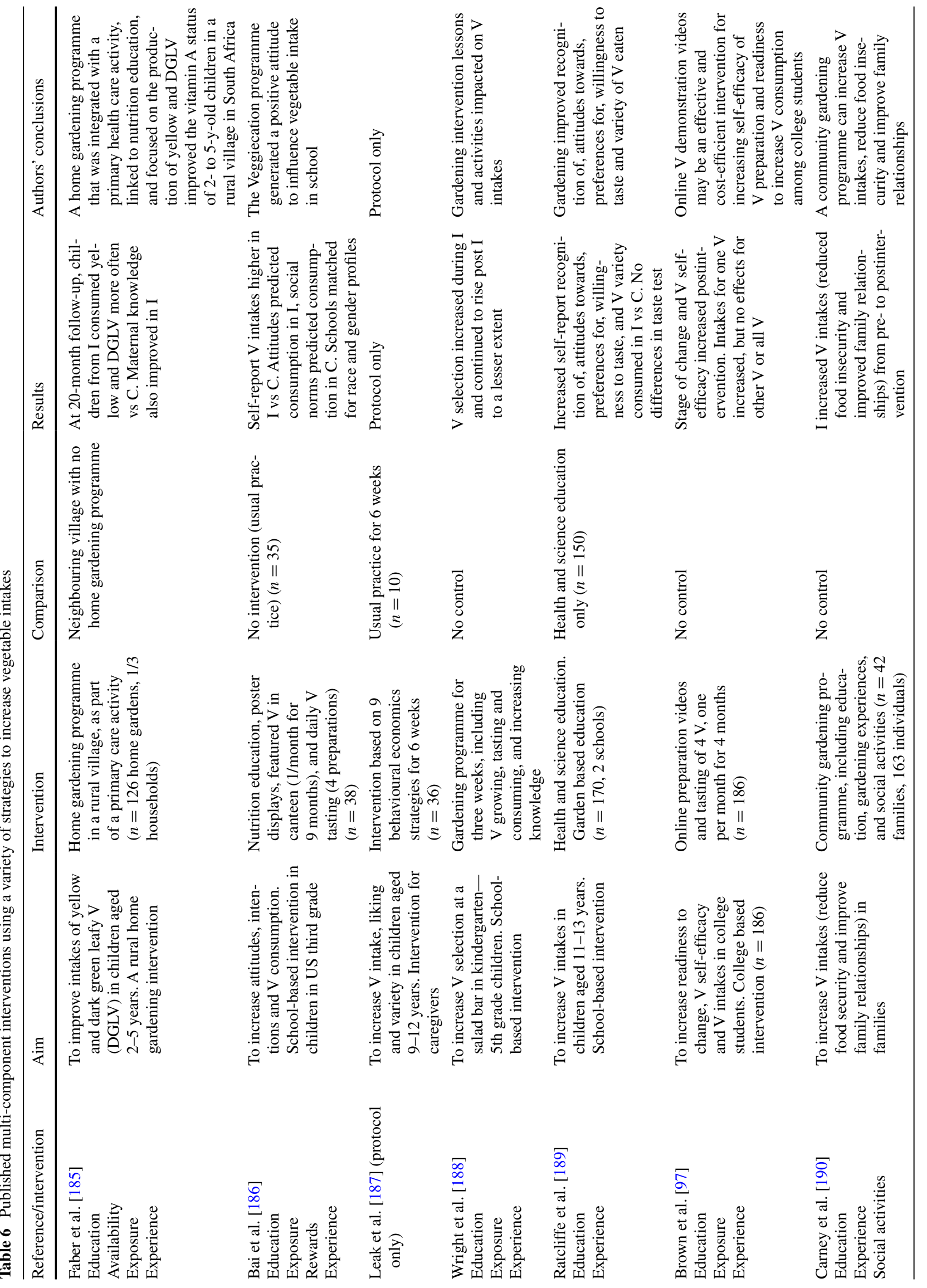




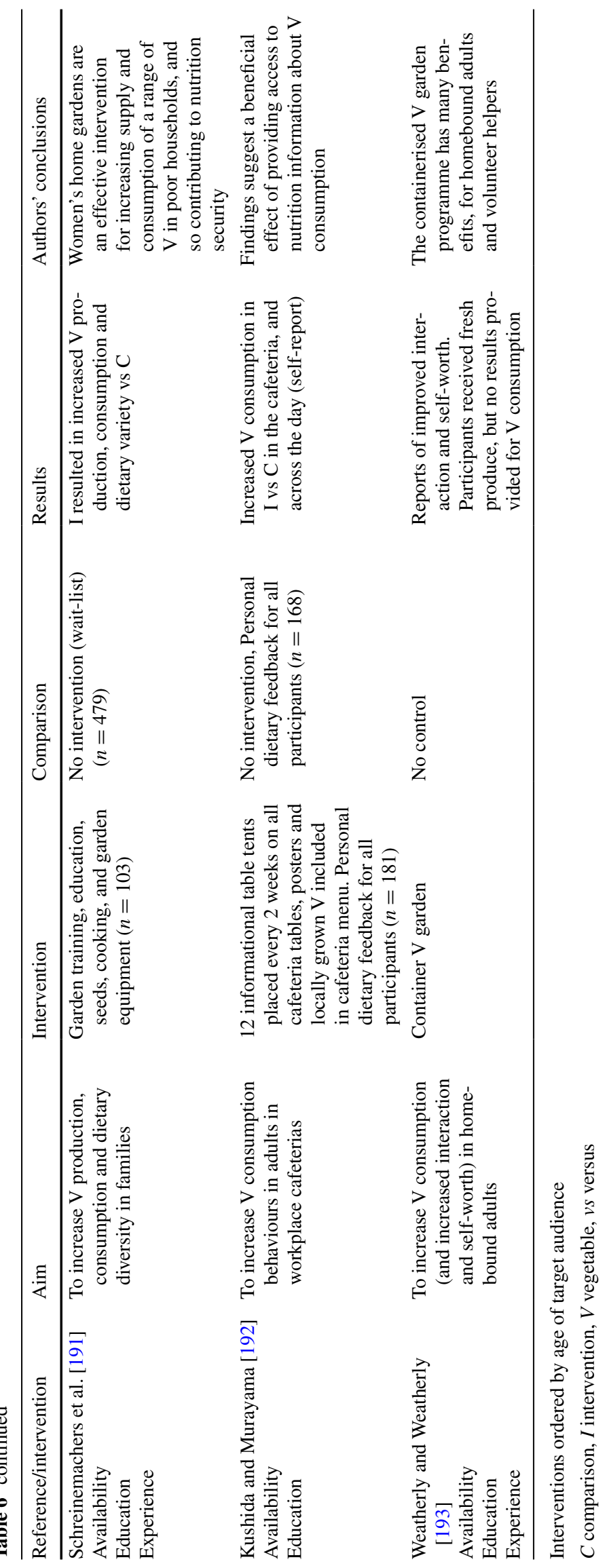




\section{Multi-component interventions}

Multi-component interventions involve a combination of strategies (Table 6). Ten of these interventions were found. Again all the published reports evaluating these interventions report success, but again multiple measures are often taken, which demonstrate varying degrees of benefit. These types of intervention can also be time-consuming and costly to implement. Success is furthermore not easily attributable to the combination of many strategies as opposed to the use of any single one.

\section{Discussion}

While a variety of successful strategies for increasing vegetable intakes have been tried, evaluated and published, evaluation periods are typically short, effect sizes can be small, and those studies that use longer follow-up periods often report reductions in effect size as follow-up periods are extended. These findings are unsurprising and have persuaded many researchers to recommend repeated interventions or a combination of interventions with the hope of improving long-term benefits. However, cost-effectiveness is rarely considered, yet cost-effectiveness becomes an increasing concern in long-lasting and multi-component interventions. Further work is clearly still required. A greater number and variety of intervention evaluations would increase the evidence base, and more reliably inform future policies. Longer-term follow-ups for interventions are imperative, and consideration of more sustainable behaviours or the more sustainable elements of behaviour, such as habit formation or behavioural norm changes, would be of value.

While the review highlights strategies of benefit furthermore, the review also identified noticeable absences. Based on the search strategies and current literature, very few interventions were identified specifically for adolescents or older individuals. The eating attitudes, practices and intakes of these groups are known to differ from those of other members of the population, and the simple generalisation of successful strategies from other population groups may not occur. Adolescence is a period of rapid development, from physical, cognitive and social perspectives, and changes to eating practices and dietary intake during this period are well reported [194]. Studies in this group on barriers to consumption identify constraints largely similar to those in younger children, but also identify an increased recognition of cognitive factors. Strategies then that involve education may be particularly beneficial. Older individuals similarly will experience changes in physical and cognitive abilities, many of which will have an impact on eating practices and food intake [195-197]. Barriers specifically to vegetable consumption in this group have not been identified as far as we are aware, but barriers to fruit and vegetable consumption are similar to those for other adults [195, 196], although the impact of demographic characteristics and environmental factors tend to be exacerbated. Changes to living circumstances for example, will impact negatively on existing impacts as a result of availability, cost and cooking abilities [195-197].

Vegetable consumption is also known to be low in individuals of low education and of low socio-economic status [198], and these factors are specifically highlighted as barriers to increasing consumption, yet few of the interventions published to date focus on or even include individuals with these demographics. There are some exceptions-the intervention by Clarke et al. [184] focuses specifically on individuals using community pantries, and many of the studies in the developing world focus not only on increasing vegetable intakes but also on sustainable vegetable provision and improved food security [185, 191], but more work is clearly needed in relation to socio-economic disparities. Interventions that improve fruit and vegetable intakes are available [199]. Increased efforts to reduce socio-economic disparities, however, are often requested [200-203], and concerns that intervention success is most easily achieved in those of little need of benefit are difficult to allay.

Consideration of the barriers to vegetable consumption suggests that many of the strategies that have shown success so far in certain groups may be beneficial for other groups. Almost all individuals will arguably benefit from increasing vegetable intakes, and the strategies found to be successful in one population group may easily transfer to another. Exposure type strategies to increase liking, for example, have shown effects for fruit consumption in older adults as well as children [204], although vegetables were not specifically investigated here. We recommend careful consideration of barriers however, and caution against a 'one size fits all' approach. While interventions may be successful across individual and population groups, testing is clearly required. At present, there is a real lack of comparisons between interventions-i.e. interventions have not been compared, e.g. in the same age group or population, with the exception of comparisons of differing exposure and conditioning strategies in young children. This lack of comparison may reflect the early nature of the field, but even where multi-component interventions have been successful, identification of the successful component/components is rarely undertaken. With a view to lasting impact and cost-effectiveness, comparison of interventions, or the identification of more effective intervention components would clearly be of value.

Several types of broader population-based interventions have also not yet been considered specifically for vegetable consumption. Strategies such as pricing and 
marketing interventions, improved product provision, government subsidies, and population-wide awareness and education campaigns [205-207] specifically for vegetables do not yet exist or have not yet been evaluated as far as we are aware. In some countries, WHO recommendations have been separated for fruit and vegetables. Dutch consumers are asked to consume $2+2$ ( 2 portions of fruit and 2 portions of vegetables per day), and Australian consumers are asked to aim for $2+5$ ( 2 portions of fruit and 5 portion of vegetables per day), but these types of recommendations rely heavily on an individual's ability to identify and categorise fruits and vegetables, and limited work suggests that consumers find this difficult $[41,104]$.

\section{Limitations of the review}

While our review has identified a number and variety of interventions, we have only considered the published literature, and our search strategy is likely to be biased towards articles published in English and away from related grey literature, such as lay publications and conference proceedings. Due to the early nature of the research area, publication bias is also highly likely. There is a noticeable absence of publications that report failures, or that demonstrate cost-inefficiency or other negative impacts of interventions. We also chose not to attempt to combine interventions. Due to the early nature of the research area, the limited number of studies available per intervention type, and high heterogeneity between study methodologies, we considered combination to be inappropriate.

\section{Future directions}

There is an urgent need for the development and evaluation of interventions to target all population groups. Interventions are particularly required for certain population groups, including adolescents, older adults and those of low socioeconomic status. Interventions for groups 'at risk' of disease may also be beneficial, given the often increased success of interventions in these individuals [1]. Assessments of the long-term benefits, sustainability and cost-effectiveness of interventions are also clearly required. While many interventions report success, effect sizes are typically small, long-term follow-up is rarely undertaken and studies that do report follow-up often fail to find sustained benefits. Interventions with a focus on long-term benefits and sustained behaviour change are required, as is increased work understanding the principles underlying behaviour change and behaviour change maintenance. Comparisons between interventions, to identify those of greatest likely benefit, would also be of interest.

\section{Conclusion}

In conclusion, increasing evidence suggests health benefits from the increased consumption specifically of vegetables, yet barriers to increasing intakes are prevalent, and while successful interventions have been published, the true value of these, both in cost-efficiency and sustainability are yet to be determined. Considerable further work is needed in developing new and adapting existing interventions for all population groups, and in evaluating benefit and cost-efficiency over the longer term.

Acknowledgments This work is part of EU/FP7 Funded VeggiEAT project (Grant No. PIAP-GA-2013-612326). The funder had no input into study design, data collection or analysis, or manuscript preparation and revision.

Contributions of authors K.M.A. led and undertook the systematic review and wrote the manuscript, A.H. and H.H. also undertook the systematic review, and reviewed and offered critical comments on the manuscript. All other authors reviewed and offered critical comments on the manuscript.

\section{Compliance with ethical standards}

Conflict of interest L. Depezay and D. Morizet are employees of Bonduelle, Villeneuve D'Ascq, France. There are no other competing interests.

Open Access This article is distributed under the terms of the Creative Commons Attribution 4.0 International License (http://creativecommons.org/licenses/by/4.0/), which permits unrestricted use, distribution, and reproduction in any medium, provided you give appropriate credit to the original author(s) and the source, provide a link to the Creative Commons license, and indicate if changes were made.

\section{References}

1. Woodside JV, Young IS, McKinley MC (2013) Fruits and vegetables: measuring intake and encouraging increased consumption. Proc Nutr Soc 72:236-245

2. Oyebode O, Gordon-Dseagu V, Walker A, Mindell JS (2014) Fruit and vegetable consumption and all-cause, cancer and CVD mortality: analysis of Health Survey for England data. J Epidemiol Community Health 68:856-862

3. Wang X, Ouyang Y, Liu J et al (2014) Fruit and vegetable consumption and mortality from all causes, cardiovascular disease, and cancer: systematic review and dose-response meta-analysis of prospective cohort studies. BMJ 349:g4490

4. Dauchet L, Amouyel P, Hercberg S, Dallongeville J (2006) Fruit and vegetable consumption and risk of coronary heart disease: a meta-analysis of cohort studies. J Nutr 136:2588-2593

5. Dauchet L, Amouyel P, Dallongeville J (2005) Fruit and vegetable consumption and risk of stroke: a meta-analysis of cohort studies. Neurology 65:1193-1197

6. Hu D, Huang J, Wang Y, Zhang D, Qu Y (2014) Fruits and vegetables consumption and risk of stroke: a meta-analysis of prospective cohort studies. Stroke 45:1613-1619 
7. Savica V, Bellinghieri G, Kopple JD (2010) The effect of nutrition on blood pressure. Ann Rev Nutr 30:365-401

8. Lanham New SA (2006) Fruit and vegetables: the unexpected natural answer to the question of osteoporosis prevention? Am J Clin Nutr 83:1254-1255

9. Astrup A, Dyerberg J, Selleck M, Stender S (2008) Nutrition transition and its relationship to the development of obesity and related chronic diseases. Obes Rev 9(Suppl 1):48-52

10. Ledoux TA, Hingle MD, Baranowksi T (2011) Relationship of fruit and vegetable intake with adiposity: a systematic review. Obes Rev 12:e143-e150

11. Lamport DJ, Saunders C, Butler LT, Spencer JP (2014) Fruits, vegetables, $100 \%$ juices, and cognitive function. Nutr Rev 72:774-789

12. Loef M, Walach H (2012) Fruit, vegetables and prevention of cognitive decline or dementia: a systematic review of cohort studies. J Nutr Health Ageing 16:626-630

13. American Institute for Cancer Research and World Cancer Research Fund. Food, Nutrition, Physical Activity and the Prevention of Cancer: A Global Perspective. (2007) American Institute for Cancer Research, Washington, DC

14. Jin J, Ouyang Z, Wang Z (2014) Association of fruit and vegetables with the risk of nasopharyngeal cancer: evidence from a meta-analysis. Sci Rep. 4:5229

15. Li B, Jiang G, Zhang G et al (2014) Intake of vegetables and fruit and risk of esophageal adenocarcinoma: a meta-analysis of observational studies. Eur J Nutr 53:1511-1521

16. McCall DO, McGartland CP, McKinley MC et al (2009) Dietary intake of fruit and vegetables improves microvascular function in hypertensive subjects in a dose-dependent manner. Circulation 119:2153-2160

17. Macready AL, George TW, Chong MF et al (2014) Flavonoidrich fruit and vegetables improve microvascular reactivity and inflammatory status in men at risk of cardiovascular diseaseFLAVURS: a randomized controlled trial. Am J Clin Nutr 99:479-489

18. Yeon JY, Kim HS, Sung MK (2012) Diets rich in fruits and vegetables suppress blood biomarkers of metabolic stress in overweight women. Prev Med 54(Suppl):S109-S115

19. Gibson A, Edgar JD, Neville CE et al (2012) Effect of fruit and vegetable consumption on immune function in older people: a randomized controlled trial. Am J Clin Nutr 96:1429-1436

20. Tanumihardjo SA, Valentine AR, Zhang Z, Whigham LD, Lai HJ, Atkinson RL (2009) Strategies to increase vegetable or reduce energy and fat intake induce weight loss in adults. Exp Biol Med 234:542-552

21. Liu RH (2013) Health-promoting components of fruits and vegetables in the diet. Adv Nutr 4:384S-392S

22. Slavin JL, Lloyd B (2012) Health benefits of fruits and vegetables. Adv Nutr 3:506-516

23. de Pee S, West CE, Permaesih D, Martuti S, Muhilal HJ (1998) Orange fruit is more effective than are dark-green, leafy vegetables in increasing serum concentrations of retinol and beta-carotene in schoolchildren in Indonesia. Am J Clin Nutr 68:1058-1067

24. Sharma S, Sheehy T, Kolonel L (2014) Sources of vegetables, fruits and vitamins $\mathrm{A}, \mathrm{C}$ and $\mathrm{E}$ among five ethnic groups: results from a multiethnic cohort study. Eur J Clin Nutr 68:384-391

25. Słupski J, Gębczyński P, Korus A, Lisiewska Z (2014) Effect of the method of preparation for consumption on calcium retention, calcium:phosphorus ratio, nutrient density and recommended daily allowance in fourteen vegetables. Int J Food Sci Nutr 65:458-464

26. Gunn CA, Weber JL, Coad J, Kruger MC (2013) Increasing fruits and vegetables in midlife women: a feasibility study. Nutr Res 33:543-551
27. Bongoni R, Verkerk R, Dekker M, Steenbekkers LP (2014) Consumer behaviour towards vegetables: a study on domestic processing of broccoli and carrots by Dutch households. J Hum Nutr Diet 28:219-225

28. Jiménez-Monreal AM, García-Diz L, Martínez-Tomé M, Mariscal M, Murcia MA (2009) Influence of cooking methods on antioxidant activity of vegetables. J Food Sci 74:H97-H103

29. Knecht K, Sandfuchs K, Kulling SE, Bunzel D (2015) Tocopherol and tocotrienol analysis in raw and cooked vegetables: a validated method with emphasis on sample preparation. Food Chem 169:20-27

30. Nagao A, Kotake-Nara E, Hase M (2013) Effects of fats and oils on the bioaccessibility of carotenoids and vitamin $\mathrm{E}$ in vegetables. Biosci Biotechnol Biochem 77:1055-1060

31. Vinha AF, Alves RC, Barreira SV, Costa AS, Oliveira MB (2015) Impact of boiling on phytochemicals and antioxidant activity of green vegetables consumed in the Mediterranean diet. Food Funct 6:1157-1163

32. Morris MC, Evans DA, Tangney CC, Bienias JL, Wilson RS (2006) Associations of vegetable and fruit consumption with age-related cognitive change. Neurology. 67:1370-1376

33. Oskarsson V, Sadr-Azodi O, Orsini N, Andrén-Sandberg Å, Wolk A (2013) Vegetables, fruit and risk of non-gallstonerelated acute pancreatitis: a population-based prospective cohort study. Gut 62:1187-1192

34. Villegas R, Shu XO, Gao YT et al (2008) Vegetable but not fruit consumption reduces the risk of type 2 diabetes in Chinese women. J Nutr 138:574-580

35. Yang Y, Zhang D, Feng $N$ et al (2014) Increased intake of vegetables, but not fruit, reduces risk for hepatocellular carcinoma: a meta-analysis. Gastroenterology 147:1031-1042

36. Anderson AS, Cox DN, McKellar S, Reynolds J, Lean MEJ, Mela DJ (1998) Take five: a nutrition education intervention to increase fruit and vegetable intakes: Impact on attitudes towards dietary change. Brit J Nutr 80:133-140

37. Brug J, de Vet E, de Nooijer J, Verplanken B (2006) Predicting fruit consumption: cognitions, intention, and habits. J Nutr Educ Behav 38:73-81

38. Ransley JK, Greenwood DC, Cade JE et al (2007) Does the school fruit and vegetable scheme improve children's diet? A non-randomised controlled trial. J Epidemiol Community Health 61:699-703

39. Sandeno C, Wolf G, Drake T, Reicks M (2000) Behavioral strategies to increase fruit and vegetable intake by fourth- through sixth-grade students. J Am Diet Assoc 100:828-830

40. Trudeau E, Kristal AR, Patterson RE (1998) Demographic and psychosocial predictors of fruit and vegetable intakes differ. Implications for dietary interventions. JADA 98:1412-1417

41. Glasson C, Chapman K, James E (2011) Fruit and vegetables should be targeted separately in health promotion programmes: differences in consumption levels, barriers, knowledge and stages of readiness for change. Public Health Nutr 14:694-701

42. European Food Safety Authority (2008) Concise Database summary statistics-total population. http://www.efsa.europa.eu/en/ datexfoodcdb/datexfooddb.htm. Accessed 10 March 2015

43. United States Department of Agriculture (2010) http://www.ers. usda.gov/Data/FoodConsumption/FoodAvailSpreadsheets.htm. Accessed 10 March 2015

44. Kamphius CBM, Giskes K, de Bruijn GJ, Wendel-Vos W, Brug J, von Lenthe FJ (2006) Environmental determinants of fruit and vegetable determinants among adults: a systematic review. Brit J Nutr 96:620-635

45. Perry CL, Bishop DB, Taylor G et al (1998) Changing fruit and vegetable consumption among children: the 5-a-day power plus program in St Paul, Minnesota. Am J Public Health 88:603-609 
46. Neville CE, McKinley MC, Draffin CR et al (2015) Participating in a fruit and vegetable intervention trial improves longer term fruit and vegetable consumption and barriers to fruit and vegetable consumption: a follow-up of the ADIT study. Int J Behav Nutr Phys Act 12:158

47. Bosetti C, Filomeno M, Riso P et al (2012) Cruciferous vegetables and cancer risk in a network of case-control studies. Ann Oncol 23:2198-2203

48. Liu YT, Dai JJ, Xu CH et al (2012) Greater intake of fruit and vegetables is associated with lower risk of nasopharyngeal carcinoma in Chinese adults: a case-control study. Cancer Causes Control 23:589-599

49. Masala G, Assedi M, Bendinelli B et al (2012) Fruit and vegetables consumption and breast cancer risk: the EPIC Italy study. Breast Cancer Res Treat 132:1127-1136

50. Polesel J, Serraino D, Negri E et al (2013) Consumption of fruit, vegetables, and other food groups and the risk of nasopharyngeal carcinoma. Cancer Causes Control 24:1157-1165

51. Luo AJ, Wang FZ, Luo D et al (2015) Consumption of vegetables may reduce the risk of liver cancer: results from a metaanalysis of case-control and cohort studies. Clin Res Hepatol Gastroenterol 39:45-51

52. Yao B, Yan Y, Ye X et al (2014) Intake of fruit and vegetables and risk of bladder cancer: a dose-response metaanalysis of observational studies. Cancer Causes Control 25:1645-1658

53. Aune D, Chan DS, Vieira AR et al (2012) Fruits, vegetables and breast cancer risk: a systematic review and meta-analysis of prospective studies. Breast Cancer Res Treat 134:479-493

54. Wang Q, Chen Y, Wang X, Gong G, Li G, Li C (2014) Consumption of fruit, but not vegetables, may reduce risk of gastric cancer: results from a meta-analysis of cohort studies. Eur $\mathbf{J}$ Cancer 50:1498-1509

55. Koushik A, Spiegelman D, Albanes D et al (2012) Intake of fruits and vegetables and risk of pancreatic cancer in a pooled analysis of 14 cohort studies. Am J Epidemiol 176:373-386

56. Vieira AR, Vingeliene S, Chan DS et al (2015) Fruits, vegetables, and bladder cancer risk: a systematic review and metaanalysis. Cancer Med 4:136-146

57. Carter P, Gray LJ, Troughton J, Khunti K, Davies MJ (2010) Fruit and vegetable intake and incidence of type 2 diabetes mellitus: systematic review and meta-analysis. BMJ 341:c4229

58. Cooper AJ, Forouhi NG, Ye Z et al (2012) Fruit and vegetable intake and type 2 diabetes: EPIC-InterAct prospective study and meta-analysis. Eur J Clin Nutr 66:1082-1092

59. Li M, Fan Y, Zhang X et al (2014) Fruit and vegetable intake and risk of type 2 diabetes mellitus: meta-analysis of prospective cohort studies. BMJ Open 5(4):e005497

60. Wu Y, Zhang D, Jiang X, Jiang W (2015) Fruit and vegetable consumption and risk of type 2 diabetes mellitus: a dose response meta-analysis of prospective cohort studies. Nutr Metab Cardiovasc Dis 25:140-147

61. Takata Y, Xiang YB, Yang G et al (2013) Intakes of fruits, vegetables, and related vitamins and lung cancer risk: results from the Shanghai Men's Health Study (2002-2009). Nutr Cancer 65:51-61

62. Tsai AC, Chang TL, Chi SH (2012) Frequent consumption of vegetables predicts lower risk of depression in older Taiwanese-results of a prospective population-based study. Public Health Nutr 15:1087-1092

63. Chen GC, Lv DB, Pang Z, Liu QF (2013) Fruits and vegetables consumption and risk of non-Hodgkin's lymphoma: a metaanalysis of observational studies. Int J Cancer 133:190-200

64. Han B, Li X, Yu T (2014) Cruciferous vegetables consumption and the risk of ovarian cancer: a meta-analysis of observational studies. Diagn Pathol 9:7
65. Liu X, Lv K (2013) Cruciferous vegetables intake is inversely associated with risk of breast cancer: a meta-analysis. Breast 22:309-313

66. Liu B, Mao Q, Cao M, Xie L (2012) Cruciferous vegetables intake and risk of prostate cancer: a meta-analysis. Int J Urol 19:134-141

67. Liu B, Mao Q, Lin Y, Zhou F, Xie L (2013) The association of cruciferous vegetables intake and risk of bladder cancer: a meta-analysis. World J Urol 31:127-133

68. Liu B, Mao Q, Wang X et al (2013) Cruciferous vegetables consumption and risk of renal cell carcinoma: a meta-analysis. Nutr Cancer 65:668-676

69. Wu QJ, Yang Y, Vogtmann E et al (2013) Cruciferous vegetables intake and the risk of colorectal cancer: a meta-analysis of observational studies. Ann Oncol 24:1079-1087

70. Zhao J, Zhao L (2013) Cruciferous vegetables intake is associated with lower risk of renal cell carcinoma: evidence from a meta-analysis of observational studies. PLoS ONE 8:e75732

71. Key TJ (2011) Fruit and vegetables and cancer risk. Br J Cancer 104:6-11

72. Fulton SL, McKinley MC, Young IS, Cardwell CR, Woodside JV (2014) The effect of increasing fruit and vegetable consumption on overall diet: a systematic review and meta-analysis. Critical Rev Food Sci Nutr. doi:10.1080/10408398.2012.72791

73. Brug J, Tak NI, te Velde SJ, Bere E, de Bourdeaudhuij I (2008) Taste preferences, liking and other factors related to fruit and vegetable intakes among schoolchildren: results from observational studies. Br J Nutr 99(suppl 1):S7-S14

74. Gibson EL, Wardle J, Watts CJ (1998) Fruit and vegetable consumption, nutritional knowledge and beliefs in mothers and children. Appetite 31:205-228

75. Wardle J, Cooke LJ, Gibson EL, Sapochnik M, Sheiham A, Lawson M (2003) Increasing children's acceptance of vegetables; a randomized controlled trial of parent-led exposure. Appetite 40:155-162

76. Dovey TM, Staples PA, Gibson EL, Halford JCG (2008) Food neophobia and 'picky/fussy' eating in children: a review. Appetite 50:181-193

77. Mustonen S, Oerlemans P, Tuorila H (2012) Familiarity with and affective responses to foods in 8-11-year-old children: the role of food neophobia and parental education. Appetite 58:777-780

78. Kelder SH, Perry CL, Klepp KI, Lytle L (1994) Longitudinal tracking of adolescent smoking, physical activity and food choice behaviors. Am J Pub Health 84:1121-1126

79. Poelman AAM, Delahunty CM, de Graaf C (2015) Vegetable preparation practices for 5-6 years old Australian children as reported by their parents; relationships with liking and consumption. Food Qual Pref 42:20-26

80. Bjelland M, Brantsæter AL, Haugen M, Meltzer HM, Nystad W, Andersen LF (2013) Changes and tracking of fruit, vegetables and sugar-sweetened beverages intake from 18 months to 7 years in the Norwegian Mother and Child Cohort Study. BMC Public Health 13:793

81. Burnier D, Dubois L, Girard M (2011) Exclusive breastfeeding duration and later intake of vegetables in preschool children. Eur J Clin Nutr 65:196-202

82. Valmórbida JL, Vitolo MR (2014) Factors associated with low consumption of fruits and vegetables by preschoolers of low socio-economic level. J Pediatr 90:464-471

83. Sweetman C, McGowan L, Croker H, Cooke L (2011) Characteristics of family mealtimes affecting children's vegetable consumption and liking. JADA 111:269-273

84. Wroten KC, O’Neil CE, Stuff JE, Liu Y, Nicklas TA (2012) Resemblance of dietary intakes of snacks, sweets, fruit, and 
vegetables among mother-child dyads from low income families. Appetite 59:316-323

85. Zeinstra GG, Koelen MA, Kok FJ, van der Laan, de Graaf C (2009) Parental child-feeding strategies in relation to Dutch children's fruit and vegetable intake. Pub Health Nutr. 13:787-796

86. Koui E, Jago R (2008) Associations between self-reported fruit and vegetable consumption and home availability of fruit and vegetables among Greek primary-school children. Pub Health Nutr 11:1142-1148

87. Melbye EL, Øverby NC, Øgaard T (2012) Child consumption of fruit and vegetables: the roles of child cognitions and parental feeding practices. Pub Health Nutr 15:1047-1055

88. Giskes K, Turrell G, Patterson C, Newman B (2002) Socioeconomic differences in fruit and vegetable consumption among Australian adolescents and adults. Publ Health Nutr 5:663-669

89. Cullen KW, Baranowski T, Rittenberry L, Cosart C, Hebert D, de Moor C (2001) Child-reported family and peer influences on fruit, juice and vegetable consumption: reliability and validity of measures. Health Educ Res 16:187-200

90. Hendy HM, Raudenbush B (2000) Effectiveness of teacher modelling to encourage food acceptance in preschool children. Appetite 34:61-76

91. Peltzer K, Pengpid S (2010) Fruits and vegetables consumption and associated factors among in-school adolescents in seven African countries. Int J Public Health 55:669-678

92. Draxten M, Fulkerson JA, Friend S, Flattum CF, Schow R (2014) Parental role modeling of fruits and vegetables at meals and snacks is associated with children's adequate consumption. Appetite 78:1-7

93. Middlestadt SE, Lederer AM, Smith NK et al (2013) Determinants of middle-school students asking parents for fruits and vegetables: a theory-based salient belief elicitation. Public Health Nutr. 16:1971-1978

94. Larson NI, Neumark-Sztainer DR, Harnack LJ, Wall MM, Story MT, Eisenberg ME (2008) Fruit and vegetable intake correlates during the transition to young adulthood. Am J Prev Med 35:33-37

95. Darian JC, Tucci L (2013) Developing marketing strategies to increase vegetable consumption. J Cons Marketing 5:427-435

96. McMahon AT, Tapsell L, Williams P, Jobling J (2013) Baby leafy green vegetables: providing insight into an old problem? An exploratory qualitative study examining influences on their consumption. Health Promot J Austr 24:68-71

97. Brown KN, Wengreen HJ, Vitale TS, Anderson JB (2011) Increased self-efficacy for vegetable preparation following an online, skill-based intervention and in-class tasting experience as a part of a general education college nutrition course. Am J Health Promot. 26:14-20

98. Vihotogbe-Sossa CN, Akissoe NH, Anihouvi VB et al (2012) Endogenous knowledge of four leafy vegetables used by rural populations in Benin. Ecol Food Nutr 51:22-39

99. Kremer-Sadlik T, Morgenstern A, Peters C et al (2015) Eating fruits and vegetables. An ethnographic study of American and French family dinners. Appetite 89:84-92

100. Myhre JB, Løken EB, Wandel M, Andersen LF (2014) Meal types as sources for intakes of fruits, vegetables, fish and whole grains among Norwegian adults. Public Health Nutr 11:1-11

101. Golding J, Steer C, Emmett P, Bartoshuk LM, Horwood J, Smith GF (2009) Associations between the ability to detect a bitter taste, dietary behaviour and growth: a preliminary report. Ann NY Acad Sci 1170:563-567

102. Knaapila A, Silventoinen K, Broms U et al (2011) Food neophobia in young adults: genetic architecture and relation to personality, pleasantness and use frequency of foods, and body mass index-a twin study. Behav Genet 41:512-521
103. Tornwall O, Silventoinen K, Hiekkalinna T (2014) Identifying flavor preference subgroups. Genetic basis and related eating behavior traits. Appetite 75:1-10

104. Brown JL, Wenrich TR (2012) Intra-family role expectations and reluctance to change identified as key barriers to expanding vegetable consumption patterns during interactive family-based program for appalachian low-income food preparers. JAND 112:1188-1200

105. Wenrich TR, Brown JL, Wilson RT, Lengerich EJ (2012) Impact of a community-based intervention on serving and intake of vegetables among low-income, rural Appalachian families. J Nutr Educ Behav 44:36-45

106. Izumi BT, Zenk SN, Schulz AJ, Mentz GB, Wilson C (2011) Associations between neighborhood availability and individual consumption of dark-green and orange vegetables among ethnically diverse adults in Detroit. JADA. 111:274-279

107. Yen ST, Tan AK (2012) Who are eating and not eating fruits and vegetables in Malaysia? Int J Pub Health 57:945-951

108. Claro RM, Monteiro CA (2010) Family income, food prices, and household purchases of fruits and vegetables in Brazil. Rev Saude Publica 44:1014-1020

109. Franchini B, Poínhos R, Klepp KI, Vaz de Almeida MD (2013) Fruit and vegetables: intake and sociodemographic determinants among Portuguese mothers. Ann Nutr Metab 63:131-138

110. Kiadaliri AA (2013) Demographic and socioeconomic differences in fruit and vegetables consumption, 2007-2009: a province-level study in Iran. Int J Prev Med 4:831-840

111. Dijkstra SC, Neter JE, Brouwer IA, Huisman M, Visser M (2014) Adherence to dietary guidelines for fruit, vegetables and fish among older Dutch adults; the role of education, income and job prestige. J Nutr Health Ageing 18:115-121

112. Gatto NM, Ventura EE, Cook LT, Gyllenhammer LE, Davis JN (2012) LA Sprouts: a garden-based nutrition intervention pilot program influences motivation and preferences for fruits and vegetables in Latino youth. JAND. 112:913-920

113. Sweitzer SJ, Ranjit N, Calloway EE et al (2014) Examining how adding a booster to a behavioral nutrition intervention prompts parents to pakc more vegetables and whole grains in their preschool children's sack lunches. Behav Med 1-9 [Epub ahead of print]

114. Uglem S, Stea TH, Kjøllesdal MK, Frølich W, Wandel M (2013) A nutrition intervention with a main focus on vegetables and bread consumption among young men in the Norwegian National Guard. Food Nutr Res 57. doi:10.3402/fnr. v57i0.21036

115. Imai $S$, Matsuda $M$, Hasegawa $G$ et al (2011) A simple meal plan of 'eating vegetables before carbohydrate' was more effective for achieving glycemic control than an exchange-based meal plan in Japanese patients with type 2 diabetes. Asia Pac J Clin Nutr 20:161-168

116. Snee LS, Nerukar VR, Dooley DA, Efird JT, Shovic AC, Nerukar PV (2011) Strategies to improve palatability and increase consumption intentions for Momordica charantia (bitter melon): a vegetable commonly used for diabetes management. Nutr J 10:78

117. Wall DE, Least C, Gromis J, Lohse B (2012) Nutrition education intervention improves vegetable-related attitude, selfefficacy, preference and knowledge of fourth-grade students. $\mathbf{J}$ School Health 82:37-43

118. Poelman AAM, Delahunty CM (2011) The effect of preparation method and typicality of colour on children's acceptance for vegetables. Food Qual Pref 22:355-364

119. Poelman AAM, Delahunty CM, de Graaf C (2013) Cooking time, but not cooking method affects children's acceptance of Brassica vegetables. Food Qual Pref 28:441-448 
120. Barends C, de Vries JH, Mojet J, de Graaf C (2013) Effects of repeated exposure to either vegetables or fruit on infant's vegetable and fruit acceptance at the beginning of weaning. Food Qual Pref 29:157-165

121. Bouhlal S, Issanchou S, Nicklaus S (2011) The impact of salt, fat and sugar levels on toddler food intake. Br J Nutr 105:645-653

122. Savage JS, Peterson J, Marini M, Bordi PL Jr, Birch LL (2013) The addition of a plain or herb-flavored reduced-fat dip is associated with improved preschoolers' intake of vegetables. JAND. 113:1090-1095

123. Bouhlal S, Chabanet C, Issanchou S et al (2013) Salt content impacts food preferences and intake among children. PLoS One 8:e53971

124. Morizet D, Depezay L, Combris P, Picard D, Giboreau A (2012) Effect of labeling on new vegetable dish acceptance in preadolescent children. Appetite 59:399-402

125. Ahearn WH (2003) Using simultaneous presentation to increase vegetables consumption in a mildly selective child with autism. J Appl Behav Anal 36:361-365

126. Remy E, Issanchou S, Chabanet C, Nicklaus S (2013) Repeated exposure of infants at complementary feeding to a vegetable puree increases acceptance as effectively as flavor-flavor learning and more effectively than flavor-nutrient learning. J Nutr 143:1194-1200

127. Mennella JA, Nicklaus S, Jagolino AL, Yourshaw LM (2008) Variety is the spice of life: strategies for promoting fruit and vegetable acceptance during infancy. Physiol Behav 94:29-38

128. Mennella JA, Kennedy JM, Beauchamp GK (2006) Vegetable acceptance by infants: effects of formula flavors. Early Hum Dev 82:463-468

129. Hetherington MM, Schwartz C, Madrelle J et al (2015) A stepby-step introduction to vegetables at the beginning of complementary feeding. The effects of early and repeated exposure. Appetite 84:280-290

130. Maier A, Chabanet C, Schaal B, Issanchou S, Leathwood P (2007) Effects of repeated exposure on acceptance of initially disliked vegetables in 7-month old infants. Food Qual Pref. 18:1023-1032

131. Caton SJ, Ahern SM, Remy E, Nicklaus S, Blundell P, Hetherington MM (2013) Repetition counts: repeated exposure increases intake of a novel vegetable in UK pre-school children compared to flavour-flavour and flavour-nutrient learning. Br J Nutr 109:2089-2097

132. Barends C, de Vries JH, Mojet J, de Graaf C (2014) Effects of starting weaning exclusively with vegetables on vegetable intake at the age of 12 and 23 months. Appetite 81:193-199

133. Ahern SM, Caton SJ, Blundell P, Hetherington MM (2014) The root of the problem: increasing root vegetable intake in preschool children by repeated exposure and flavour learning. Appetite 80:154-160

134. Hausner H, Olsen A, Møller P (2012) Mere exposure and flavour-flavour learning increase 2-3 year-old children's acceptance of a novel vegetable. Appetite 58:1152-1159

135. Bouhlal S, Issanchou S, Chabanet C et al (2014) 'Just a pinch of salt'. An experimental comparison of the effect of repeated exposure and flavor-flavor learning with salt or spice on vegetable acceptance in toddlers. Appetite 83:209-217

136. de Wild VW, de Graaf C, Jager G (2013) Effectiveness of flavour nutrient learning and mere exposure as mechanisms to increase toddler's intake and preference for green vegetables. Appetite 64:89-96

137. Holley CE, Haycraft E, Farrow C (2015) 'Why don't you try it again?' A comparison of parent led, home based interventions aimed at increasing children's consumption of a disliked vegetable. Appetite 87:215-222
138. Fildes A, van Jaarsveld CH, Wardle J, Cooke L (2014) Parentadministered exposure to increase children's vegetable acceptance: a randomized controlled trial. JAND 114:881-888

139. Anzman-Frasca S, Savage JS, Marini ME, Fisher JO, Birch LL (2012) Repeated exposure and associative conditioning promote preschool children's liking of vegetables. Appetite 58:543-553

140. O'Connell ML, Henderson KE, Luedicke J, Schwartz MB (2012) Repeated exposure in a natural setting: a preschool intervention to increase vegetable consumption. JAND 112:230-234

141. Correia DC, O'Connell M, Irwin ML, Henderson KE (2014) Pairing vegetables with a liked food and visually appealing presentation: promising strategies for increasing vegetable consumption among preschoolers. Child Obes 10:72-76

142. Fisher JO, Mennella JA, Hughes SO, Liu Y, Mendoza PM, Patrick H (2012) Offering "dip" promotes intake of a moderatelyliked raw vegetable among preschoolers with genetic sensitivity to bitterness. JAND. 112:235-245

143. Havermans RC, Jansen A (2007) Increasing children's liking of vegetables through flavour-flavour learning. Appetite 48:259-262

144. Hendy HM, Williams KE, Camise TS (2005) "Kids Choice" school lunch program increases children's fruit and vegetable acceptance. Appetite 45:250-263

145. Cooke LJ, Chambers LC, Añez EV et al (2011) Eating for pleasure or profit: the effect of incentives on children's enjoyment of vegetables. Psychol Sci 22:190-196

146. Corsini N, Slater A, Harrison A, Cooke L, Cox DN (2013) Rewards can be used effectively with repeated exposure to increase liking of vegetables in 4-6-year-old children. Pub Health Nutr 16:942-951

147. Noradilah MJ, Zahara AM (2012) Acceptance of a test vegetable after repeated exposures among preschoolers. Malays J Nutr 18:67-75

148. Wardle J, Herrera ML, Cooke L, Gibson EL (2003) Modifying children's food preferences: the effects of exposure and reward on acceptance of an unfamiliar vegetable. Eur J Clin Nutr 57:341-348

149. Lakkakula A, Geaghan J, Zanovec M, Pierce S, Tuuri G (2010) Repeated taste exposure increases liking for vegetables by lowincome elementary school children. Appetite 55:226-231

150. Johnston CA, Palcic JL, Tyler C, Stansberry S, Reeves RS, Foreyt JP (2011) Increasing vegetable intake in Mexican-American youth: a randomized controlled trial. JADA 111:716-720

151. Zeinstra GG, Koelen MA, Kok FJ, de Graaf C (2009) Children's hard-wired aversion to pure vegetable tastes. A 'failed' flavour-nutrient learning study. Appetite 52:528-530

152. Olsen A, Ritz C, Kraaij LW, Møller P (2012) Children's liking and intake of vegetables: a school-based intervention study. Food Qual Pref 23:90-98

153. Heath P, Houston-Price C, Kennedy OB (2014) Let's look at leeks! Picture books increase toddlers' willingness to look at, taste and consume unfamiliar vegetables. Front Psychol 5:191

154. Byrne E, Nitzke S (2002) Preschool children's acceptance of a novel vegetable following exposure to messages in a storybook. J Nutr Educ Behav 34:211-213

155. de Droog SM, Buijzen M, Valkenburg PM (2014) Enhancing children's vegetable consumption using vegetable-promoting picture books. The impact of interactive shared reading and character-product congruence. Appetite 73:73-80

156. Coulthard H, Harris G, Fogel A (2014) Exposure to vegetable variety in infants weaned at different ages. Appetite 78:89-94

157. Maier AS, Chabanet C, Schaal B, Leathwood PD, Issanchou SN (2008) Breastfeeding and experience with variety early in weaning increase infants' acceptance of new foods for up to two months. Clin Nutr. 27:849-857

158. de Wild VW, de Graaf C, Boshuizen HC, Jager G (2015) Influence of choice on vegetable intake in children: an in-home study. Appetite 91:1-6 
159. Spill MK, Birch LL, Roe LS, Rolls BJ (2010) Eating vegetables first: the use of portion size to increase vegetable intake in preschool children. Am J Clin Nutr 91:1237-1243

160. Spill MK, Birch LL, Roe LS, Rolls BJ (2011) Serving large portions of vegetable soup at the start of a meal affected children's energy and vegetable intake. Appetite 57:213-219

161. Spill MK, Birch LL, Roe LS, Rolls BJ (2011) Hiding vegetables to reduce energy density: an effective strategy to increase children's vegetable intake and reduce energy intake. Am J Clin Nutr 94:735-741

162. Mathias KC, Rolls BJ, Birch LL et al (2012) Serving larger portions of fruits and vegetables together at dinner promotes intake of both foods among young children. JAND 112:266-270

163. Bucher T, Siegrist M, van der Horst K (2014) Vegetable variety: an effective strategy to increase vegetable choice in children. Pub Health Nutr 17:1232-1236

164. Wansink B, Just DR, Payne CR, Klinger MZ (2012) Attractive names sustain increased vegetable intake in schools. Prev Med $55: 330-332$

165. Just DR, Wansink B (2009) Smarter lunchrooms: using behavioural economics to improve meal selection. Choices Mag Food Farm Resour Issues 24:19-24

166. Redden JP, Mann T, Vickers Z, Mykerezi E, Reicks M, Elsbernd S (2015) Serving first in isolation increases vegetable intake among elementary school children. PLoS One 10:e0121283

167. Reicks M, Redden JP, Mann T, Mykerezi E, Vickers Z (2012) Photographs in lunch tray compartments and vegetable consumption among children in elementary school cafeterias. JAMA 307:784-785

168. Bucher T, van der Horst K, Siegrist M (2011) Improvement of meal composition by vegetable variety. Public Health Nutr 14:1357-1363

169. Blatt AD, Roe LS, Rolls BJ (2011) Hidden vegetables: an effective strategy to reduce energy intake and increase vegetable intake in adults. Am J Clin Nutr 93:756-763

170. Meengs JS, Roe LS, Rolls BJ (2012) Vegetable variety: an effective strategy to increase vegetable intake in adults. JAND 112:1211-1215

171. Rolls BJ, Roe LS, Meengs JS (2010) Portion size can be used strategically to increase vegetable consumption in adults. Am J Clin Nutr 91:913-922

172. Shenoy SF, Kazaks AG, Holt RR et al (2010) The use of a commercial vegetable juice as a practical means to increase vegetable intake: a randomized controlled trial. Nutr J 9:38

173. Shenoy SF, Poston WS, Reeves RS et al (2010) Weight loss in individuals with metabolic syndrome given DASH diet counseling when provided a low sodium vegetable juice: a randomized controlled trial. Nutr J 9:8

174. Zeinstra GG, Renes RJ, Koelen MA, Kok FJ, de Graaf C (2010) Offering choice and its effects on Dutch children's liking and consumption of vegetables: a randomized controlled trial. Am J Clin Nutr 91:349-356

175. Domínguez PR, Gámiz F, Gil M et al (2013) Providing choice increases children's vegetable intake. Food Qual Pref 30:108-113

176. Gholami M, Wiedemann A, Knoll N, Schwarzer R (2015) Mothers improve their daughters' vegetable intake: a randomized controlled trial. Psychol Health Med 20:1-7

177. Morris JL, Zidenberg-Cherr S (2002) Garden-enhanced nutrition curriculum improves fourth-grade school children's knowledge of nutrition and preferences for some vegetables. JADA 102:91-93

178. Morgan PJ, Warren JM, Lubans DR, Saunders KL, Quick GI, Collins CE (2010) The impact of nutrition education with and without a school garden on knowledge, vegetable intake and preferences and quality of school life among primary-school students. Pub Health Nutr 13:1931-1940

179. Robinson E, Blissett J, Higgs S (2011) Recall of vegetable eating affects future predicted enjoyment and choice of vegetables in British University undergraduate students. JADA 111:1543-1548

180. Stok FM, Verkooijen KT, de Ridder DTD, de Wit JBF, de Vet E (2014) How norms work: self-identification, attitude, and self-efficacy mediate the relation between descriptive social norms and vegetable intake. Appl Psychol Health Well-Being 6:230-250

181. Ogawa Y, Tanabe N, Honda A et al (2011) Point-of-purchase health information encourages customers to purchase vegetables: objective analysis by using a point-of-sales system. Environ Health Prev Med 16:239-246

182. Rahman MM, Islam MA, Mahalanabis D, Chowdhury S, Biswas E (1994) Impact of health education on the feeding of green leafy vegetables at home to children of the urban poor mothers of Bangladesh. Pub Health 108:211-218

183. Tabak RG, Tate DF, Stevens J, Siega-Riz AM, Ward DS (2012) Family ties to health program: a randomized intervention to improve vegetable intake in children. J Nutr Educ Behav 44:166-171

184. Clarke P, Evans SH, Hovy EH (2011) Indigenous message tailoring increases consumption of fresh vegetables by clients of community pantries. Health Commun 26:571-582

185. Faber M, Phungula MA, Venter SL, Dhansay MA, Benadé AJ (2002) Home gardens focusing on the production of yellow and dark-green leafy vegetables increase the serum retinol concentrations of 2-5-y-old children in South Africa. Am J Clin Nutr 76:1048-1054

186. Bai Y, Suriano L, Wunderlich SM (2014) Veggiecation: a novel approach to improve vegetable consumption among schoolaged children. J Nutr Educ Behav 46:320-321

187. Leak TM, Swenson A, Vickers $Z$ et al (2015) Testing the effectiveness of in-home behavioral economics strategies to increase vegetable intake, liking, and variety among children residing in households that receive food assistance. J Nutr Educ Behav 47:E1-E9

188. Wright W, Rowell L (2010) Examining the effect of gardening on vegetable consumption among youth in kindergarten through fifth grade. WMJ 109:125-129

189. Ratcliffe MM, Merrigan KA, Rogers BL, Goldberg JP (2011) The effects of school garden experiences on middle school-aged students' knowledge, attitudes, and behaviors associated with vegetable consumption. Health Promot Pract 12:36-43

190. Carney PA, Hamada JL, Rdesinski R et al (2012) Impact of a community gardening project on vegetable intake, food security and family relationships: a community-based participatory research study. J Community Health 37:874-881

191. Schreinemachers P, Patalagsa MA, Islam MR et al (2015) The effect of women's home gardens on vegetable production and consumption in Bangladesh. Food Secur 7:97-107

192. Kushida O, Murayama N (2014) Effects of environmental intervention in workplace cafeterias on vegetable consumption by male workers. J Nutr Educ Behav 46:350-358

193. Weatherly L, Weatherly K (1990) Containerized vegetable gardening for homebound patients. Caring 9:52-54

194. Mooney E, Farley H, Strugnell C (2004) Dieting among adolescent females-some emerging trends. Int J Cons Stud 28:347-354

195. Appleton KM, McGill R, Neville C, Woodside JV (2010) Barriers to increasing fruit and vegetable intakes in the older population of Northern Ireland: low levels of liking and low awareness of current recommendations. Pub Health Nutr 13:514-521 
196. Appleton KM, McGill R, Woodside JV (2009) Fruit and vegetable consumption in older people in Northern Ireland: levels and patterns. Br J Nutr 102:949-953

197. Best RL, Appleton KM (2013) Investigating protein consumption in older adults: a focus group study. J Nutr Educ Behav 45:751-755

198. Giskes K, Avendan M, Brug J, Kunst AE (2009) A systematic review of studies on socioeconomic inequalities in dietary intakes associated with weight gain and overweight/obesity conducted among European adults. Obes Rev 658:413-429

199. AbuSabha R, Namjoshi D, Klein A (2013) Increasing access and affordability of produce improves perceived consumption of vegetables in low-income seniors. JADA 111:1549-1555

200. Agudo A, Ibanez R, Amiano P et al (2008) Consumption of cruciferous vegetables and glucosinolates in a Spanish adult population. Eur J Clin Nutr 62:324-331

201. Galobardes BC, Irala-Estevez JD, Groth M et al (2000) A systematic review of socioeconomic differences in food habits in Europe: consumption of fruit and vegetables. Eur J Clin Nutr 54:706-714

202. Roos G, Johansson L, Kasmel A, Klumbiene J, Prattala $\mathrm{R}$ (2001) Disparities in vegetable and fruit consumption:
European cases from the north to the south. Pub Health Nutr 4:35-43

203. Tohill BC, Seymour J, Serdula M, Kettel-Khan L, Rolls BJ (2004) What epidemiologic studies tell us about the relationship between fruit and vegetable consumption and body weight. Nutr Rev 62:365-374

204. Appleton KM (2013) Increases in fruit intakes in low consumers of fruit following two community-based repeated exposure interventions. Br J Nutr 109:795-801

205. Curhan RC (1974) The effects of merchandising and temporary promotional activities on the sales of fresh fruits and vegetables in supermarkets. J Marketing Res 11:286-294

206. Glanz K, Yaroch AL (2004) Strategies for increasing fruit and vegetable intake in grocery stores and communities: policy, pricing, and environmental change. Prev Med 39 suppl 2:S75-S80

207. Pérez-Cueto FJ, Aschemann-Witzel J, Shankar B et al (2012) Assessment of evaluations made to healthy eating policies in Europe: a review within the EATWELL Project. Pub Health Nutr 15:1489-1496 